\title{
Appropriation of a representational tool in a second-language classroom
}

\author{
Yun Wen • Chee-Kit Looi • Wenli Chen
}

Received: 15 August 2014 / Accepted: 13 January 2015 / Published online: 27 January 2015

(C) International Society of the Learning Sciences, Inc. 2015

\begin{abstract}
While the affordances of face-to-face and online environments have been studied somewhat extensively, there is relatively less research on how technology-mediated learning takes place across multiple media in the networked classroom environment where face-to-face and online interactions are intertwined, especially in the context of language learning. This case study contextually investigates the appropriation of a representational tool by students in small groups, in the context of collaborative second language writing activities. In this paper, micro-analysis of cross-media interactions is deployed to unravel how different groups of students evolve alternative approaches to appropriating the technology. The study explores the beneficial affordances of a representational tool that supplement face-to-face communication for second language learning, and draws implications for the design of collaborative L2 learning in networked classrooms.
\end{abstract}

Keywords Representational tool $\cdot$ Networked classroom learning $\cdot \mathrm{CSCL} \cdot \mathrm{Computer}$-supported language learning

\section{Introduction}

The use of computer-supported collaborative learning (CSCL) is more and more commonplace in language-learning classrooms (Dooly 2011). Technical artifacts can augment spoken and gestural communication between co-present collaborators (Roschelle 1994; Suthers et al. 2003), that can be embedded in classrooms where face-to-face communication is still a main channel for interaction (Lingnau et al. 2003).

\footnotetext{
Y. Wen $(\bowtie)$

Computer-human Interaction in Learning and Instruction (CHILI) Lab, EPFL, Lausanne, Switzerland e-mail: yun.wen@epfl.ch

C.-K. Looi $\cdot$ W. Chen

National Institute of Education, Nanyang Technological University, Singapore, Singapore

C.-K. Looi

e-mail: chee-kit.looi@nie.edu.sg

W. Chen

e-mail: wenli.chen@nie.edu.sg
} 
The educational benefits of representational tools for learning have been recognized, such as when selecting relevant information, organizing information into coherent formats, or relating it to prior understanding (e.g., Liu 2011; Shaw 2010; Stull and Mayer 2007). Yet most of the studies focus on reporting the positive or negative effects of the representational tools on the students' learning performance or learning motivations (Hwang et al. 2014), or accentuate how to design or script a representational tool in online learning. Less attention has been paid to how groups of learners appropriate a representational tool in a classroom environment in which face-to-face communication is an integral part of the learning interactions, and to how technical artifacts mediate face-to-face communication (with Overdijk and van Diggelen 2008 as an exception).

CSCL research is mostly concerned with investigating group interaction processes in virtual online environments (Cakir et al. 2009; Stahl and Hesse 2010; Suthers et al. 2007). Although the affordances of face-to-face and online environments have long been studied separately, there is relatively less research on how technology-mediated learning takes place across multiple media in a networked environment (Dillenbourg and Traum 2006; Dyke et al. 2011; Looi et al. 2009; Medina and Suthers 2008; Suthers et al. 2003, 2011). In a networked learning classroom with the presence of a representational tool, some activities are computer-based, while some are not. Enacting effective collaborative activities may be daunting tasks for teachers and learners, even if they have previous experience in enacting collaborative activities. In a dynamic classroom environment, even though there are stable characteristics of a representational tool that are generalizable over different groups or settings, the tool can still be appropriated in unexpected ways (Larusson and Alterman 2007; Overdijk and van Diggelen 2008; Dwyer and Suthers 2006).

In recent years, a kind of generic representational tool-Group Scribbles (GS), which includes a graphical shared workspace - was developed for enabling collaborative generation, collection, and aggregation of ideas through a shared space based on individual efforts and social sharing of notes in graphical and textual forms (Roschelle et al. 2007). Situated in a Chinese-as-second-language (L2) learning classroom setting, the present paper aims at exploring the beneficial affordances of the GS representational tool that supplement face-to-face communication facilitating productive small group interaction. This paper presents a case study carried out in a Singapore secondary school to analyze how different small groups used GS to complete a collaborative writing activity. We adopted a microanalysis of interactions to examine the interplay between medium transition (the switch between GS-based and face-toface interactions) and cognitive processing at the group level.

This study sought to contribute to expanding the theoretical base of computer-supported collaborative language learning by stressing small group interactions, and intersubjective meaning making in language learning. It sought to contribute practically to understanding the potential of multimedia technology in networked L2 classrooms, and would thereby inform activity design of collaborative L2 learning in such a setting. Methodologically, the study is resonant with calls from CSCL research directions that are concerned with real classroom learning and multimedia/ multimodal interactions (Medina and Suthers 2008; Suthers et al. 2003, 2011). It provides a workable approach to exploring how small-group interactions interweaving social and cognitive dimensions take place in dual-interaction (both face-to-face and online) environments.

\section{Theoretical perspectives}

Investigating interactions in language learning from sociocultural perspectives

When CSCL research is approached within a disciplinary perspective of language learning, or more specifically L2 learning, less interesting findings seem to have been produced than with 
science or mathematics learning. One reason may be that the field of language learning has long been dominated by traditional cognitive perspectives that emphasize the individual internalization of mental processes and the development of grammatical competence (Firth and Wagner 1997; Ortega 2012). This contrasts with CSCL studies undergirded by sociocultural perspectives. Although the role of technologies and the value of collaborative learning in language learning are contentious topics in the literature (e.g., Blake et al. 2008; Brodahl et al. 2011; Hartup 1996; Warschauer 1997), a majority of research concerns the development of language proficiency. The role language plays in mediating meaning making and shared understanding for the pursuit of joint intellectual activity (Elola and Oskoz 2010; Mercer 2005, 2008; Swain 2000) is somewhat neglected.

In collaborative language learning, language is not only the learning content but also the learning medium. However, this makes it challenging to analyze how group members engage in thinking together about a problem or task, how they produce knowledge artifacts (e.g., in verbal, textual, or graphic form) that integrate their different perspectives on the topic, and how they represent the shared group products that they have negotiated and made a consensus to construct. This may be the reason why most studies on technology-enabled pair/group work in language classrooms are focused on examining learners' attitudes to pair/group work in general, rather than exploring the nature of the collaboration process or the role of technology when students participate in a joint intellectual activity (Storch 2005; Shehadeh 2011).

The studies of Swain and Lapkin (Swain 2000; Swain and Lapkin 1995, 1998, 2001) argued that language use and language learning can co-occur, and more specifically, that language use mediates language learning. They stated that a collaborative task provides learners with opportunities to learn through a discussion of the language they are using, and when learners work together, their social construction of meaning by talking about language may evolve as well. In this sense, a collaborative L2 learning activity allows learners to focus on language problems and together develop a deeper understanding of language (Swain 2000). Drawing on Swain's (2000) conceptualization of collaborative dialogue (referring to a dialogue in which speakers are engaged in problem solving and knowledge construction), several L2 researchers have investigated how learners work together to solve linguistic problems and/ or co-construct language or knowledge about language (e.g., McDonough and Sunitham 2009; Watanabe and Swain 2007). Yet these studies (Wigglesworth and Storch 2012, as an exception) mainly revolve around language learning itself and pay limited attention to the concrete task that the participants carry out and to the larger context of the joint activity where they are acting (e.g., coordinating effects to proceed with group work). There are questions about how linguistic knowledge can be constructed collaboratively and how meaning making takes place in language learning through interactions with each other and with technologies.

In a CSCL environment for science learning, to trace the trajectories for scientific conceptual change, researchers have concentrated on meaning making using the concept of idea refinement; in the context of math learning, researchers have focused on interactional moves that have making, accepting, rejecting, or modifying proposals or steps in mathematics problem solving. However, in the context of language learning, there is a broad range of knowledge objects that may refer to grammatical or syntactical knowledge, or beyond them. In this paper, we use the notion of group-understanding development to investigate intellectual interaction in groups. This notion refers to the diachronic development of understanding across members of a group. Group-understanding development echoes Stahl's group cognition (2006) but refers to a broader spectrum of cognitive activities, including both the establishment of common understanding by all group members and the externalization of individual thinking that is fundamental to achieving mutual understanding and yet may not guarantee it (Jeong 2013). In this manner, this study takes into account all observable cognitive activities within a 
group to examine the interplay between medium transition and small-group learning; it matters not if during the process mutual understanding is successfully established by all. If a small group of students establishes a point of shared understanding successfully, productive groupunderstanding development is used to refer to the cognitive activity in this case. As CSCL researchers, we are interested in the role of technological tools in this process. To this aim, it is important to understand the concepts of the affordance and appropriation.

Technology affordances and appropriation

Gibson (1979) proposed the term "affordance" from the perceptual psychological perspective in developing an "ecological" alternative to cognitive approaches. This notion underscores artificial surfaces embodying specific opportunities for actions that become available to the acting agent. Later, the notion of "technology affordances" is interpreted as a dispositional action opportunity in a technological setting (Gaver 1991), and becomes appealing in CSCL research (Suthers 2006; Overdijk et al. 2012, 2014). It is not only useful in exploring the psychological claims inherent in artifacts and the rationale of technology designs (Gaver 1991), but also highlights the personalized perspectives on CSCL and the active role of learners in interacting with technology (Overdijk et al. 2014).

In line with this understanding, the design of a technology does not determine the nature of its implementation. A given technology offers affordances that may influence how learners engage in knowledge construction (Kozma 2003; Suthers and Hundhausen 2003) but do not causally determine their learning outcomes (Hakkarainen 2009; Oliver 2011; Medina and Suthers 2012). Learners can appropriate the technology for their own purposes, and this appropriation can develop over time (Medina and Suthers 2012).

The concept of appropriation, as Overdijk et al. generalized, implies "a tension between artifact-as-used and the tensions invested in the artifact by its designers" (2014, p.284). In this study we highlighted this concept because the explanatory value of affordance is limited in bringing a new technology into use (Overdijk et al. 2012, 2014) or using a technology in an unfamiliar context. This study aimed at exploring the beneficial affordances of a representational tool in the context of authentic L2 learning classroom conditions on which relatively little research has been conducted. Hence, we present and summarize the way in which the representational tool is appropriated in different small groups. Students' and teachers' intellectual resources are augmented to facilitate learning achievements only when collaborative technologies have fused with their social practices (Hakkarainen 2009). Therefore, our study is based on a case in which a representational tool has been used for a whole year, on this assumption that the teacher and students have developed a familiarity with the collaborative activities using such tool.

\section{Related work}

Representational tools

"Representation - the act of highlighting aspects of our experience and communicating them to others and ourselves - is one of the fundamental and generative activities that is at the heart of the human experience" (Enyedy 2005, p. 427). Technological devices can be used for creating and sharing externalizations, and thus these tools are often referred to as representational tools (Suthers and Hundhausen 2003). The notion of representational tools is emphasized in this study to distinguish them from other computer-mediated communication tools for dialogical communication or threaded discussion. 
Prior research on CSCL has highlighted the importance of representational aids, such as dynamic notations, knowledge maps, and simulations for collaborative learning performance (Fischer et al. 2002; Janssen et al. 2008; Slof et al. 2010; Wegerif et al. 2010). Embedding representational tools in a CSCL environment can facilitate students' construction of multimodal representations in the knowledge domain and thereby guide their interactions (Slof et al. 2010). Through representing ideas and understandings in a shared workspace, students' thinking is made public and exposed to critical scrutiny, during which cognitive development can occur (Gillies 2006; Goos et al. 2002; Liu and Kao 2007). Suthers and Hundhausen (2003) have concluded that external representations play at least three roles that are unique to situations in which a group is constructing and manipulating shared representations as part of a cognitive activity. They are: (1) initiating negotiation of meaning; (2) serving as representational proxy for purposes of gestural deixis (reference to an entity relative to the context of discourse by pointing), rather than verbal descriptions; and (3) providing a foundation for implicitly shared awareness. Although the educational benefits of representational tools are widely recognized, some studies report mixed or even negative findings about learning (e.g., Bera and Liu 2006; Elen and Clarebout 2007; van Drie et al. 2005). Van Drie et al's study (2005), for example, reported that the addition of a representational tool in the CSCL environment did not result in more co-elaborated historical reasoning in an online chat discussion. The explanation they provided is that it might be too much effort on communication in the online chat but easier in face-to-face communication. In view of this, in this study we focused on investigating medium transitions between the representational tool and face-toface communication, as well as their relationship with productive group interaction.

\section{GS affordances for collaborative learning}

Next, we present GS as an example of a representational tool, which is used in our study. The GS user interface presents the user with a two-paned window (Fig. 1). Its lower pane represents the user's personal workspace (or private board), whereas the upper pane represents the public board. The private board is provided with a virtual pad of fresh scribble sheets on which the user can draw or type. The students can share the scribble sheets by dragging them from the private board to the public board. The most essential feature of GS is the combination of a private board on which students can work individually, and group boards on which students can post their work, view others' work, and take items back to the private board for further elaboration. A student can select among multiple group board by clicking on the board number at the top right corner, and browse all other groups' postings on the public board. Hence, the tool may make intra- and inter-group interactions more convenient. Thus, students have an opportunity to exchange their ideas and provide comments for one another without physical movement in classroom environments.

Apart from features common to on-line representational tools, such as synchronicity, anonymity, and spatial arrangement of the posts, GS's design exploits specifically an affordance for "lightweight participation". This means that students can express their own ideas on a small scribble sheet quickly and with ease. Students are advised to use only one small sheet of paper for scribbling or expressing an idea. Due to the size limitations of the sheet, they have to use brief and recap phrases or sentences to express their own opinions. It does not matter whether the ideas expressed exist already or not, as the purpose of a small notepad is to encourage every individual to take the initiative to think and share. It is an efficient method to get students to participate, such as generating dozens of micro ideas without any form of organization. This affordance for "lightweight participation" fits L2 learners very well. It is 


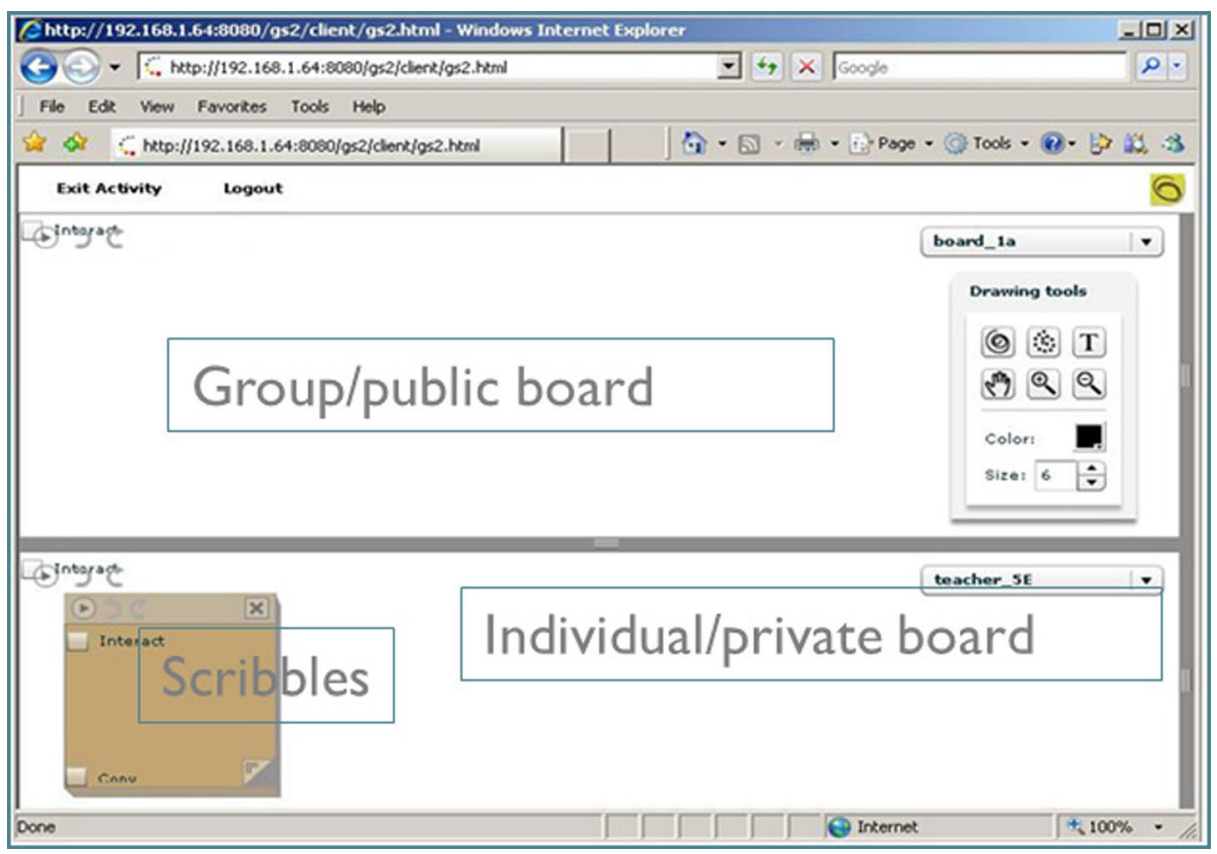

Fig. 1 The user interface of GS with a two-paned window

usually difficult for L2 learners to express themselves in long, complicated sentences or to extract the main points from long paragraphs in a short period of time. In GS, each student's contribution or post can be composed (written, sketched, or typed) quickly on a small scribble sheet. Both idea fragments and diversified words/phrases can be expressed on such scribble sheets. They may be shared democratically, organized conveniently, and improved continuously. Thus, GS affordances may be of great significance for L2 writing practice of a planning activity. Students from one class may usually come from families speaking different languages at home, and thereby may vary in their language proficiencies. Augmenting interaction using GS may provide students with high proficiency with more opportunities to review and refine peers' work products. Students with low language proficiency may have more opportunities to learn from others as well. In this way, good ideas will have a chance to be shared and improved.

Studies of the pedagogical use of GS in the classroom have shown that the classes using GS performed better than the classes not using it, as measured by traditional assessments (Looi et al. 2010). With GS, students were found to have more opportunities to participate in class discussions through both GS postings and verbal interactions, and were exposed to diverse ideas in science lessons (Chen et al. 2010; Song and Looi 2012). Drawing on classroom intervention work incorporating GS into L2 learning of Chinese language, the results of student's examination scores suggested that the students with higher language proficiency seem to profit more from collaborative learning activities than the students with lower language proficiency (Wen et al. 2011a). Although multivocal analyses of small group problem solving using GS in mathematics and science lessons have been conducted (Suthers et al. 2011; Looi et al. 2013), a better understanding of how this representational tool helps facilitate productive interaction in language learning is needed. 
Analytic frameworks for investigating interaction in CSCL

During the past decade, analytic frameworks and approaches for analyzing interaction in CSCL have become increasingly sophisticated (e.g., Baker et al. 2007; Dillenbourg and Traum 2006; Hogan et al. 2000). It is posited that the methodological uniqueness of CSCL research "is reflected in the several approaches that have been put forth to document and analyze collaborative interactions" (Puntambekar et al. 2011, p. ix). These frameworks/techniques are used for examining interaction in different representational formats (e.g., forum-based or mapping-based) and with different analytic foci and assumptions about what it means for participants to achieve a conceptually deeper level of interaction.

According to whether only the temporal issue (or the chronological dimension) is taken into account, they can be classified into two major categories: (1) the nature of the function of participants' contributions in the dialogue and (2) patterns and trajectories of participant interaction. Besides, the bulk of the analytical frameworks/techniques are applied to examine interactions happening in a single dialogue-based interaction environment (e.g., a chat tool), and only a few revolve around interactions happening in dual-interaction spaces (e.g., HmeloSilver et al. 2011; Suthers and Rosen 2011). Considering the multimodality of available interaction data, Suthers and Rosen (2011) propose a unified framework for the multi-level analysis of interaction based on their previous studies, which were concerned with uncovering the organization of interactions in the sequential record of events in a media-independent and fundamental unit of interaction - uptake (Suthers 2006; Suthers et al. 2007, 2010). Their framework provides the missing piece in the analytic ability to extract structural indicators of an activity in online collaborative environments where forum-based and mapping-based interaction spaces are intertwined (Suthers et al. 2007; Suthers and Rosen 2011). To understand how learning happens in interactions and how diverse tools are used, Hmelo-Silver and colleagues (2009 2009, 2011) suggest Chronologically-Ordered Representation of Discourse and Tool-Related Activity (CORDTRA) as a means of studying multiple aspects of coded discourse over time. Their work considers the relation of tools and discourse broadly construed. However, none of these frameworks/techniques is specific for analyzing interactions in language learning. In this study, to investigate the diachronic development of understanding across media and across members of a group, the chronological dimension is taken into account. Open coding is adopted to consider the characteristics of L2 learning in which problem solving and linguistic knowledge construction are intertwined (Swain 2000).

\section{Research question}

The overarching research question of this paper is: what is the interplay between medium transition and the group-understanding development as L2 learners accomplish a collaborative activity in a representational tool-embedded classroom?

Rather than pursuing the linear relationship between medium transition and groupunderstanding development, our study revolves around elucidating the ways in which the inscriptional devices can constrain or enhance learners' opportunities in group-understanding development in L2 learning. The role of inscriptional devices in group-understanding development is identified contextually, by their effect on and relation to the interaction that they are a part of. Meanwhile, in terms of the notion of technology affordances and appropriation, the presence of a representational tool in the classroom alone does not automatically benefit students' learning (Slof et al. 2010). The empirical data in previous studies on representational tools has shown that tools may only help students to carry out tasks when they clearly see how 
these tools can help them, and training in the use of the tool could increase the effect on collaborative activities (Bera and Liu 2006). Instead of analyzing a case longitudinally, we chose to do a case study by focusing on how students in small groups bring the tool into use with different approaches at a point in time when they have become familiarized with the tool. This paper is based on the study of a single lesson to investigate the complex process of groupunderstanding development in L2 learning in a dual-interaction environment more deeply.

\section{Method}

\section{Participants}

The subjects of this study were a class of a secondary school in Singapore (Grade 8). Singapore is known as a multi-ethnic and multilingual country, where English is the de facto national language that is used not only in official workplaces but also as the medium of instruction in the school system (Pakir 1991). Chinese, Malay, and Tamil languages are defined in specific Singaporean terms as "Mother Tongue Language (MTLs)" that are mainly used for communicating and maintaining the cultural heritage. Chinese/Mandarin language is the MTL for all ethnic Chinese.

The experimental school belongs to one of the Singapore Future schools which aim at harnessing ICT for engaged learning and keeping the education system and programs in Singapore relevant to preparing students for the future. Teachers in all subjects are required to maximize the use of various computer technologies so as to optimize class teaching and learning. Due to the frequent use of computer technologies in school, teachers and students are rather technology-savvy.

The class involved in this study consists of 6 female students and 13 male students (aged from 14 to 16). They are all ethnic Chinese students. In every GS lesson, these 19 students were separated into five groups based on their previous school final year examination scores for the Chinese language subject. A comparatively high-ability group, a medium-ability group, a comparatively low-ability group, and two mixed-ability groups were formed. In order to build and sustain the group culture, group compositions remained unchanged from the beginning until the end of the implementation of this study. The last GS lesson of their Grade 8 was selected as the case lesson on the assumption that the teacher and students had developed familiarity with GS-based collaborative activities.

\section{Learning environment and activity design}

Figure 2 shows the GS classroom environment where students sat in groups. Each student had his or her own laptop to access the GS tool. An Interactive Whiteboard was set up in front of the classroom to help the teacher to visualize and monitor the interaction processes of every group.

The selected GS lesson involves collaborative L2 writing practice of a planning activity. In the planning activity, students are required to make decisions on the ideas they intend to express and then formulate the language structure to express these ideas as they produce a text together. Students not only generate, cluster, and order ideas, but they also consider both hierarchical and structural relations among the ideas to make sure the small group's outline is internally consistent. This kind of task exploits the aforementioned GS affordances. Moreover, according to Chai (2006), writing performance is highly relevant to the planning activity, regardless of the learners' language proficiency. Students can benefit from articulating their 


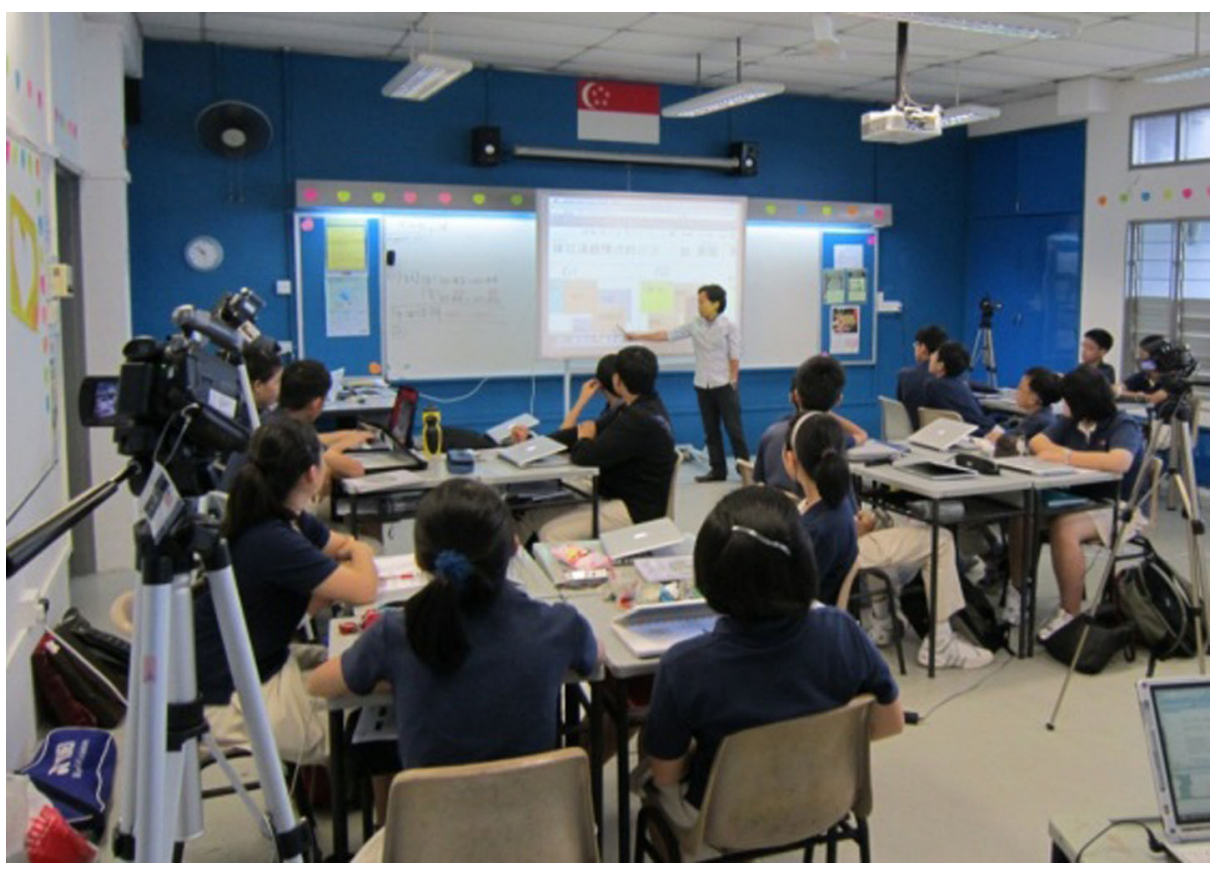

Fig. 2 GS classroom environment

ideas as they organize the task, plan the content, and air their viewpoints about the audience, purpose, and form of their text. In this way, they jointly deepen their understandings of linguistic knowledge as well as writing content and strategies.

The main learning objective of the lesson was to help students understand that an argumentative essay can be conceptualized and composed from exploring the contributing factors of a phenomenon, followed by articulating their impact and suggesting solutions if needed. The topic for the writing was “整容有罪吗” (“Is plastic surgery ethically right?”). The lesson included five main task phases (Table 1). Students were encouraged to generate their group ideas via collecting individual contributions from within the group and borrowing ideas from other groups. In the spirit of promoting and respecting cognitive diversity, the activity began with the creation and presentation of different ideas. In the subsequent phases, a synergy of ideas was sought. The final phase of idea convergence and consensus seeking could thus lead to knowledge convergence and advancement (Fisher and Mandl 2005; Wen et al. 2011b). The task was designed with the inclusion of more mutual coordinating activities which would lead to a more consistent shared knowledge and a better mutual solution. In the GS tool, a template (Fig. 3) was uploaded as the background for the group board in order to provide a visual scaffolding for students to follow the teacher's instructions and to help them pay attention to the three elements (cause, consequence, and solution) necessary in writing an argumentative essay.

Data collection and analysis

The main data sources for this study were the video data of the face-to-face and GS-based interactions in the various groups. In addition to video cameras, the iShowU screen-capturing software was installed on every student's MacBook to record all the actions of individual 
Table 1 Main phases of the collaborative planning task

\begin{tabular}{llc}
\hline Phases & Description & Time \\
\hline Before GS-based activity & $\begin{array}{l}\text { The teacher introduces the main purpose of the GS activity } \\
\text { to students and helps students to recap strategies for } \\
\text { argumentative writing. }\end{array}$ & 5 mins \\
& $\begin{array}{l}\text { Students brainstorm "reasons for the phenomenon" around } \\
\text { the given topic. }\end{array}$ & 10 mins \\
$\begin{array}{l}\text { Phase 1: } \\
\text { Brainstorming and organizing }\end{array}$ & $\begin{array}{l}\text { Students generate "consequences of the phenomenon" based } \\
\text { on the reasons given by the peer group. }\end{array}$ & 15 mins \\
$\begin{array}{l}\text { Phase 2: } \\
\text { Building upon }\end{array}$ & $\begin{array}{l}\text { Students summarize "solutions" based on the shared } \\
\text { "reasons" and "consequences", and synthesize, extract and }\end{array}$ & 15 mins \\
Achieving shared understanding & improve the big ideas for their group writing. \\
After GS-based activity & $\begin{array}{l}\text { Students present main ideas and the structure of writing } \\
\text { according to group inscriptions. The teacher summarizes } \\
\text { and comments on each group's work. }\end{array}$ & 15 mins \\
\hline
\end{tabular}

students on the computers, as well as their verbal talk and facial expressions (using the computer's webcam).

For the data analysis, all the video data were first transcribed verbatim, synchronized and presented chronologically. Then all the interaction data were coded in multiple levels with different dimensions. At the macro-level, the interaction data were coded with two dimensions - the medium and functions of interactions - using the unit of "event". An event in this study refers to a series of uninterrupted interaction moves with the same semantic content, happening through the same medium. It could be a 2-minute long conversation, as long as the participants were continuously talking about the same topic. It also could be as short as one verbal sentence or a single GS posting.

This study aims to investigate students' interactions across face-to-face and online interactional spaces. Students' interactions in the unit of event were categorized into face-to-face-based and GS-based in terms of medium, and then these events were further categorized in terms of the function performed to complete the task: whether the event is social-related or cognitive-related. Additionally, as the study is focused on exploring the trajectories of group-understanding development, any event regarding off-task issues, such as technical problems, jokes, greetings etc., would not be included in the data analysis of this study. In view of these, all the events were classified into three categories related to functions performed to complete the task:

\begin{tabular}{|c|c|c|}
\hline 整容现象产生的原因: & 这一现象导致的后果: & 解决方法: \\
\hline Caustanhao & Consequences & \\
& & \\
& & \\
& & \\
& & \\
& & \\
\end{tabular}

Fig. 3 A graphic organizer for the planning task 
cognitive-related, social-related, and off-task. In the study, the "social-related" category termed as "Regulation", refers to interactions about regulating and coordinating group work. Taking account of the characteristics of L2 learning, the "cognitiverelated" interactions were further categorized into two sub-categories: Content-related and Language-related. These categories were established as the result of a repeated process of iterating back and forth between theory and data by multiple researchers (Onrubia and Engel 2012). Table 2 shows the categories presented with examples.

Coding for the macro-level provided a "first pass" about the distribution of the interactions. At the micro-level, the interaction sequences and contextual information were taken into consideration in coding. A diagram was created to visualize the sequence of interaction events and their relations (Fig. 4).

As shown in Fig. 4, the flow from top to down denotes the time sequence. The flow of GS posting and verbal conversations is schematized in two separate columns. Their content is shown in the central big column. The information regarding participants, media and functions of interactions can be obtained from the diagram directly. Two other concepts were proposed to help identify media transition. One is "cross-media adjacency events". These are represented in solid lines with arrow $(\rightarrow$ ) to signify the adjacent cognitive meaningful events spanning different medium spaces. The other is "cross-media responses" which indicate that those cross-media interactional moves happened between GS postings and social-related/off-task events (represented in broken lines). They are represented by dotted lines $(->)$ in the diagram. Because this study concerns interactions happened in dual-interaction spaces, we focused mainly on "cross-media adjacency events".

Table 2 Categories used to identify the interaction function in groups

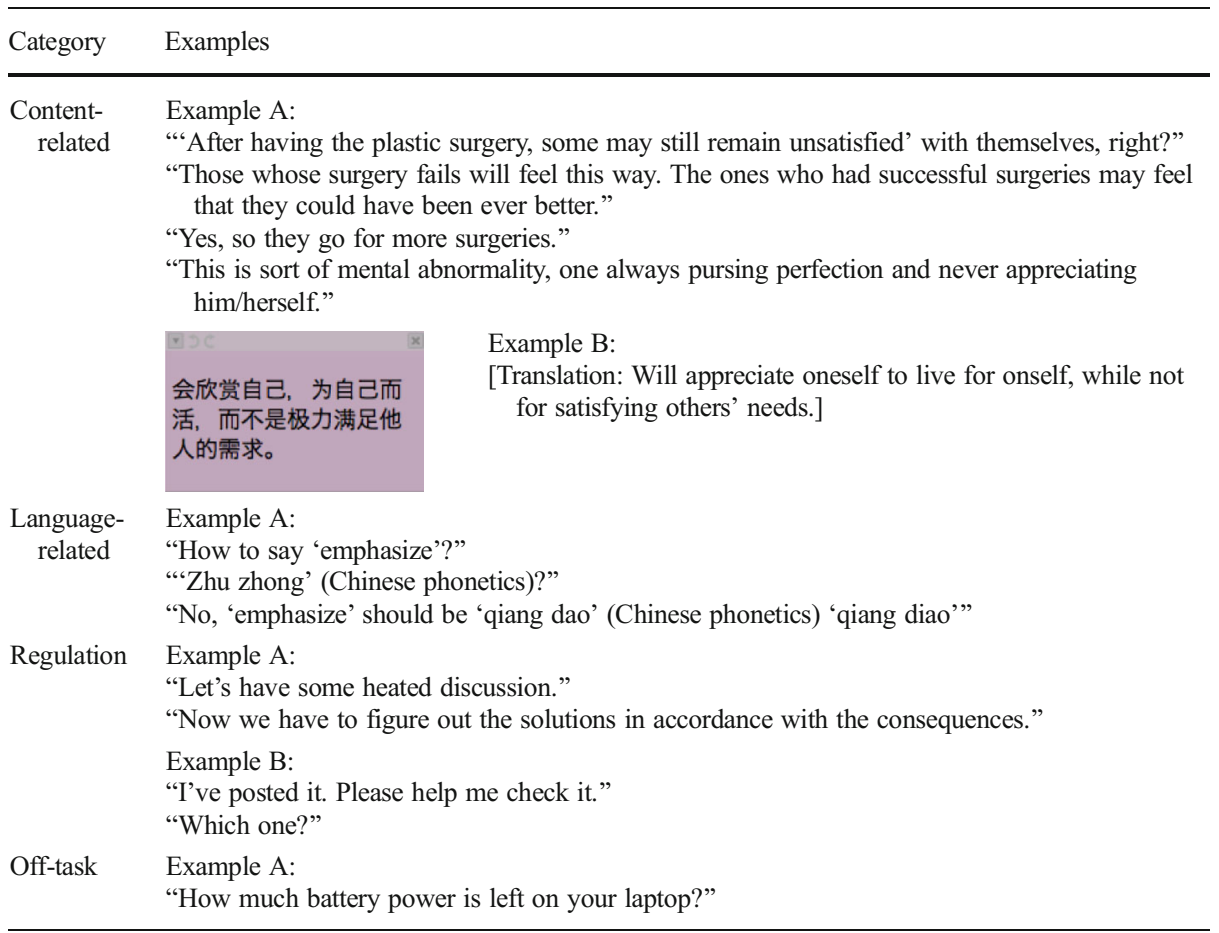




\begin{tabular}{|c|c|c|c|c|c|}
\hline \multicolumn{3}{|c|}{$\begin{array}{c}\text { Diagram } \\
\text { Representation }\end{array}$} & \multirow{2}{*}{ Content } & \multirow{2}{*}{$\begin{array}{c}\text { Particip } \\
\text { ants }\end{array}$} & \multirow{2}{*}{ Note \& Interpretation } \\
\hline GS & & Face-to-face & & & \\
\hline & & $\begin{array}{l}3 \\
\text { C } \\
4\end{array}$ & 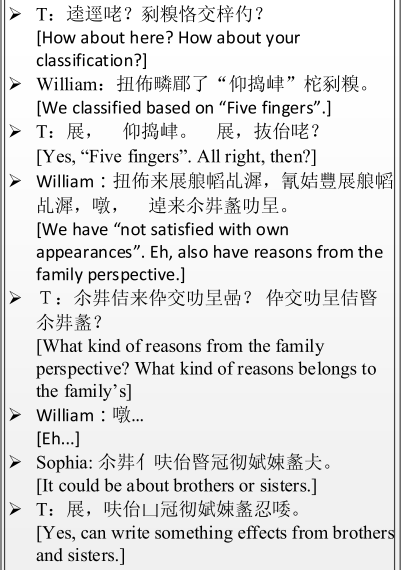 & $\begin{array}{c}\text { Teacher, } \\
\text { William, } \\
\text { and } \\
\text { Sophia }\end{array}$ & $\begin{array}{l}\text { When Group } 3 \text { was on the } \\
\text { point of re-organizing their } \\
\text { existing postings, the } \\
\text { teacher intervened and } \\
\text { asked the students about } \\
\text { their work progress. } \\
\\
\text { William responded to the } \\
\text { teacher that they had } \\
\text { contributed some ideas } \\
\text { from "the personal } \\
\text { perspective", but it is worth } \\
\text { noting that "reasons from } \\
\text { the family perspective" } \\
\text { never occur in this group's } \\
\text { previous discussion. It } \\
\text { seems that this a new idea } \\
\text { that has popped up in } \\
\text { William's own mind. }\end{array}$ \\
\hline & & $\left(\begin{array}{l}3 \\
R \\
4\end{array}\right.$ & $\begin{array}{l}>\text { Sophia: 扭柁, 扭し。 } \\
\text { [I do it, I write it] }\end{array}$ & Sophia & \\
\hline $3 \mathrm{G} 7$ & $4 .$. & & 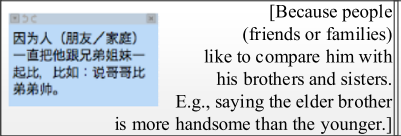 & Sophia & \\
\hline
\end{tabular}

Legend:

$3 G 1$ refers to group 3's first GS posting (the small rectangle in dotted border means the posting is not newly created).

$3 G 7$ refers to group 3's seventh GS posting

$3 C 4$ refers to group 3's fourth Content-related verbal conversation

$3 R 4$ refers to group 3's fourth Regulationrelated verbal conversation

$T$ refers to the teacher

Note:

All students are given pseudonyms

Fig. 4 Diagram for analyzing across-media interactions at the micro-level

It is also important to note that in this case study, quantitative data only provide overall descriptive information about interaction distribution in the different small groups of students, and help us select and interpret interesting excerpts for micro-level analysis.

\section{Results}

\section{Interaction distribution}

Table 3 shows the distribution of interactions in different media by different student groups. It is noteworthy that 1) the homogeneously high-ability group (Group 1) participated most actively both face-to-face and on the GS space; 2) the lowest participatory level was found in the homogeneously middle-ability group (Group 3); 3) the homogeneously low-ability group (Group 5) participated the least in face-to-face talk. In addition, we can see how task management-related communication or coordination, and even off-task interactions, did not occur in the GS environment. That means the GS environment mainly served as a shared external memory where the group kept a record of shared understandings, but not for sociallyrelated communication. Face-to-face interactional events, however, could be further classified into different categories of function (see Table 4).

The quantitative data suggested that all the groups actively participated in completing the task (off-task interactions mean $=7, S D=3.317$ ). The results indicated that group language proficiency restricted L2 learners' involvement in verbal talk, especially when they were encouraged to communicate in the target language. Yet its influence on their involvement in online interaction was not so compelling (as shown in Table 3). Groups with higher language 


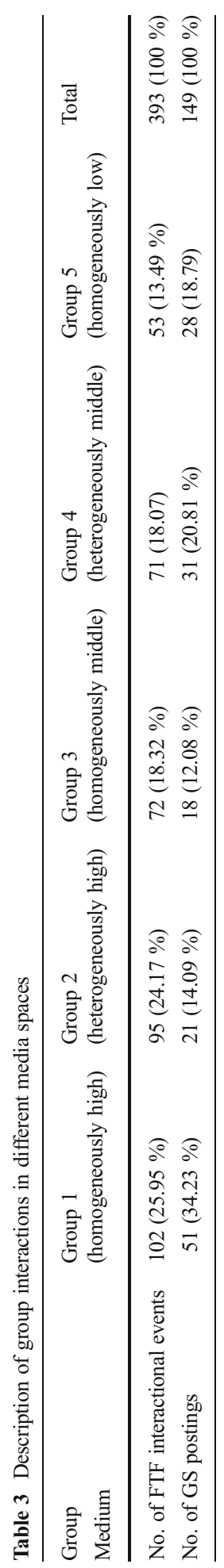




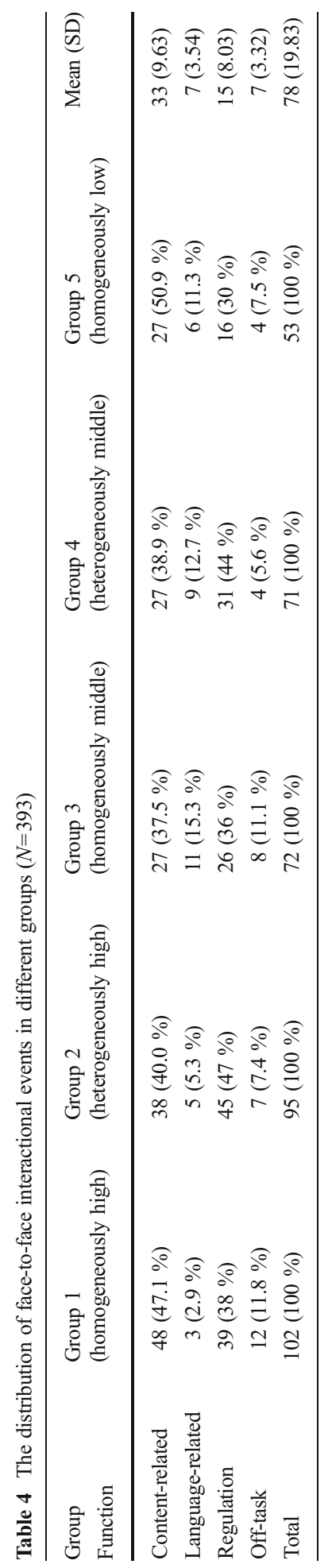


proficiency tended to focus more on content-related knowledge talk than on language-related knowledge talk (as shown in Table 4).

\section{Medium transition and group-understanding development}

Zooming in on the co-construction process of group inscriptions, the analysis of both "crossmedia adjacency events" and "cross-media responses" helped to identify the semantic and temporal relationship among face-to-face and GS-mediated interactions and to understand the kinds of situations in which group-understanding development occurred effectively. Incorporating the quantitative process information, we selected excerpts from the small group interactions that reflect critical events in the appropriation of GS, where medium transition took place. We focus mainly on excerpts from the homogeneously high-ability group (Group 1) and the homogeneously middle-ability group (Group 3 ). They were selected not only because both of them completed the group task efficiently, but also because Group 1 participated most actively on the dual spaces and Group 3 had the lowest participatory level on the GS space amongst the groups. Since our study is concerned with the use of the representational tool (GS) in multimedia interactions, we chose to focus on Group 1 and Group 3, in which the highest and lowest participatory level in the GS space were found respectively.

Excerpts 1 and 2 present the typical medium transition patterns that were extracted from Group 1 and Group 3 at Phase 1 of the activity. Excerpts 3 and 4 present the patterns that were observed in the same two groups at Phase 3 of the activity. These excerpts were selected as inter-interaction approaches of these 2 groups were apparently different at these two phases. We do not include the results of microanalysis of interactions at other phases due to space limitations. Below, each excerpt starts off with a presentation of the data in the diagram, with GS inscriptions and verbal talk placed in chronological order.

\section{Referencing and pinpointing observed in group 1 at phase 1}

Figure 5 shows how students in Group 1 started their group work and shared their individual ideas. As shown in Excerpt 1, we found that the inscriptional device mainly played two roles in group-understanding development: referencing and pinpointing. The use here of the term "referencing" refers to the subsequent elaboration and meaningful discussion of the content of the inscriptions. This referencing takes place without changing the content or creating new relevant content. The pinpointing proposed refers to the fact that no revision of the content ideas took place on the GS space, even though typos, grammatical errors, or other languagerelated problems regarding the existing posting were verbally detected. The excerpt demonstrates how and in which situations they took place.

At the beginning phase of the activity, that is Phase 1, the teacher made explicit the goals of the GS-based task (for enhancing students' collaboration, communication and critical thinking skills). The teacher asked students to think of phenomena around the given topic and to brainstorm reasons for the prevalent phenomenon of plastic surgery in society (T1). Group 1 first clarified the teacher's instruction (1R1) and worked out how to approach the group task (1R2) in a short time. When consensus had been achieved, they quickly switched to contributing ideas on the GS space. The interaction data show that all four students in Group 1 participated actively in sharing and representing their individual ideas on their group board. Before the teacher asked students to organize their postings (T4), each student first relied on their own individual work by transposing their ideas into GS notes and placing them on the shared GS space, but without sufficient verbal talk. As shown in Excerpt 1, only one crossmedia response (1G2->1R3) can be observed during that period, in which the group member 


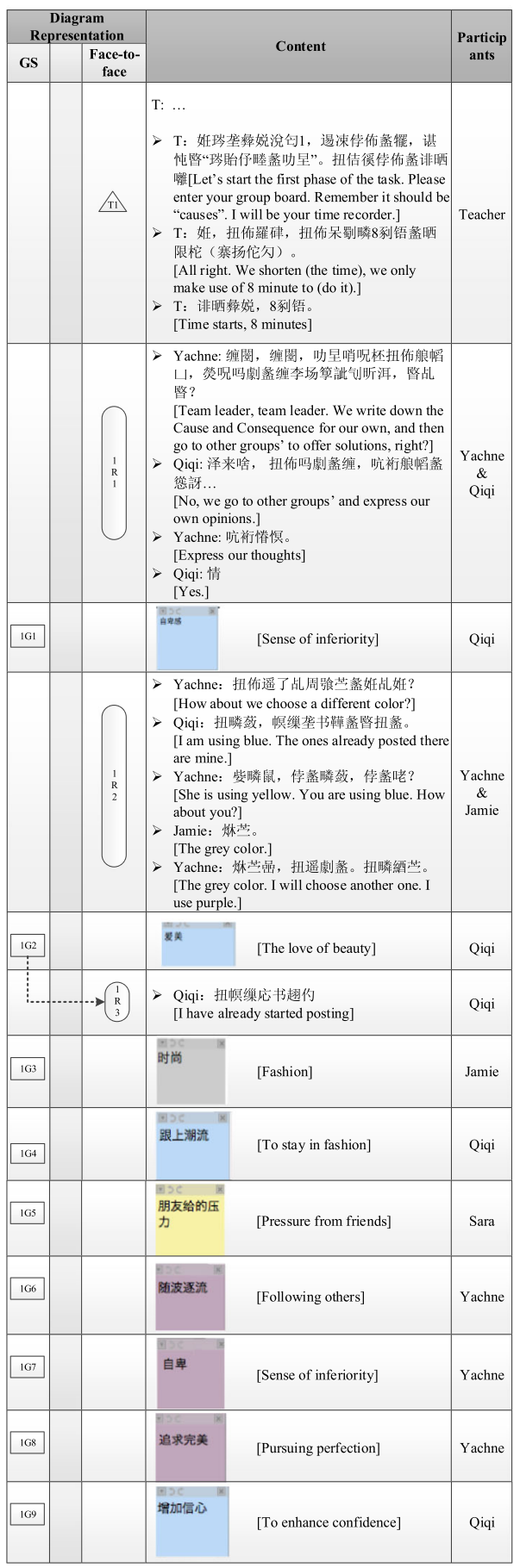

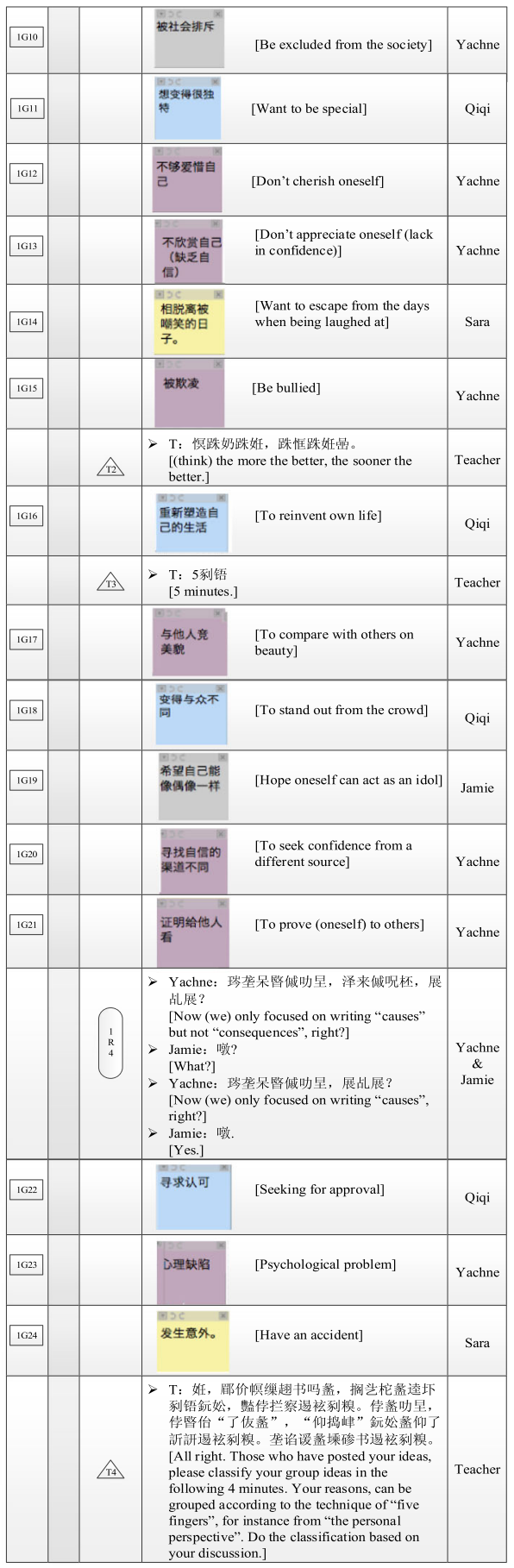

Fig. 5 Excerpt 1: Group 1's interactional events at Phase 1 


\begin{tabular}{|c|c|c|c|}
\hline & & $\begin{array}{l}>\text { Y achne: 所以我们分 } 5 \text { 行啊? } \\
\text { [So we organize them into } 5 \text { lines?] } \\
>\text { Qiqi: 就是分 “个人”、“社会” 妚有 “朋 } \\
\text { 友." } \\
\text { [Classify them into "the personal perspective", } \\
\text { "the social perspective" and "the perspective } \\
\text { from your friend".] } \\
>\text { Y achne: 恩. } \\
\text { [Yes] }\end{array}$ & $\begin{array}{c}\text { Yachne } \\
\& \\
\text { Qiqi }\end{array}$ \\
\hline & & $\begin{array}{l}\text { Y Yachne: 那我们就 } 5 \text { 行, 这样子, 横、横、 } \\
\text { 横、横、横, } 5 \text { 行. 个人的我们放第一个, } \\
\text { [Then we organize them into } 5 \text { lines, like this, } \\
\text { across, across, across, across, across, } 5 \text { lines, } \\
\text { We put "the personal perspective" first.] }\end{array}$ & Yachne \\
\hline $1 \mathrm{G}$ & & $\begin{array}{l}>\text { Qiqi: "时尚" 是"社会"吧? } \\
\text { ["Fashion" belongs to "Society" right?] } \\
>\text { Yachne: "时敞" 是潮流吧? } \\
\text { ["Fashion" is a trend, right?] } \\
>\text { Qiqi: 所以萛是“社会" } \\
\text { [So it belongs to "Society"] }\end{array}$ & $\begin{array}{c}\text { Yachne } \\
\& \\
\text { Qiqi }\end{array}$ \\
\hline & & $\begin{array}{l}>\text { Yachne: 我们先把全部拖到后果那边好不 } \\
\text { 好? } \\
\text { [H ow about we move them all to the } \\
\text { "Consequence" at first?] } \\
>\text { Qiqi: 先至哪里? } \\
\text { [First to where?] } \\
>\text { Qiqi:先揩到后果那一栏, 然后再整过未. } \\
\text { [First to the "Consequence" column and then } \\
\text { move them here.] }\end{array}$ & $\begin{array}{c}\text { Yachne } \\
\& \\
\text { Qiqi }\end{array}$ \\
\hline$-\frac{109}{\vdots}$ & & $\begin{array}{l}\text { Yachne: Ok, 现在我们来吧...第一个是 “个 } \\
\text { 人” 吗? “增加信心” } \\
\text { [Ok, let's do it...The first one, the one "to } \\
\text { enhance confidence", does it belong to "the } \\
\text { personal"] }\end{array}$ & Yachne \\
\hline
\end{tabular}

\begin{tabular}{|c|c|c|c|}
\hline 1614 & & 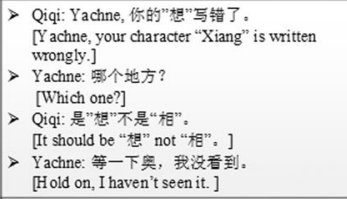 & $\begin{array}{l}\text { Yachne } \\
\& \\
\text { Qiqi }\end{array}$ \\
\hline & $\widehat{\mathrm{MS}}$ & $\begin{array}{l}>\mathrm{T} \text { : 现在讨论那个分类, 还有 } 2 \text { 分钟。 } \\
\text { [Now, focusing on di scussing organi zing } \\
\text { ideas. Two more minutes.] }\end{array}$ & Teacher \\
\hline 194 & c & 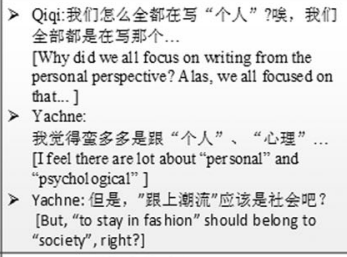 & $\begin{array}{l}\text { Qiqi, } \\
\text { Yachne } \\
\text { \& Sara }\end{array}$ \\
\hline 10 & & $\begin{array}{l}>\text { Yachne: 那我移到下面 } \\
\text { [Then I move it downwards] }\end{array}$ & Yachne \\
\hline 1010 & & $\begin{array}{l}\text { Qiqi: Then, “被社会排斥" 是跟社会。 } \\
\text { [Then, "Be excluded from the } \\
\text { society" belongs to the "social"] }\end{array}$ & Qiqi \\
\hline
\end{tabular}

Fig. 5 (continued)

(Qiqi) verbally informed other group members that she had begun posting after she published her ideas on the GS space. Following her, each group member was then actively engaged in brainstorming for vocabulary/ideas on the GS space.

Cross-media adjacency events (e.g., 1G3 $\rightarrow 1 \mathrm{C} 2,1 \mathrm{G} 9 \rightarrow 1 \mathrm{C} 3$ ) only emerged after the teacher asked them to organize the existing postings (T4). Upon receiving the instruction from the teacher, Yachne and Qiqi reached a quick consensus on how to categorize their postings, and Sara and Jamie agreed with their decision (1C1). Immediately after that, all four students made an effort to arrange their postings. As Yachne had suggested (1R5), they moved the posting over to the blank space on the right side of the board and then moved them back to the proper position in terms of the category. In these cross-media adjacency events (see, $1 \mathrm{G} 3 \rightarrow 1 \mathrm{C} 2$, $1 \mathrm{G} 9 \rightarrow 1 \mathrm{C} 3,1 \mathrm{G} 4 \rightarrow 1 \mathrm{C} 4$, and $1 \mathrm{G} 10 \rightarrow 1 \mathrm{C} 5$ ), a pattern of medium transition emerged, namely, from GS inscription to content-related talk $(G S \rightarrow C O N T)$. In this situation, we named the inscriptional device played a role of referencing in group-understanding development. Usually this type of cross-media adjacency events was followed by cross-media responses (e.g., 1C2 $\rightarrow$ $1 \mathrm{G} 3,1 \mathrm{C} 3 \rightarrow 1 \mathrm{G} 9$, and $1 \mathrm{C} 5 \rightarrow 1 \mathrm{G} 10$ ), in which students rearranged the existing postings after verbally coordinating or announcing to one another but without any revision of the posted content. In this excerpt, each student focused more on their own individual work, even though they made use of GS postings from others as references and refined their own group inscriptions.

Also in excerpt 1 , in the cross-media adjacency events: $1 \mathrm{G} 14 \rightarrow 1 \mathrm{~L} 1$, we can see another alternative pattern of medium transition - from GS inscription to language-related talk (GS $\rightarrow$ $L A N G$ ) - where inscriptional device functioned as pinpointing in group-understanding development. Yet according to the transcript data, this type of cross-media adjacency events occurred rarely in the group with high language proficiency.

In summary, the interactions of Group 1 at Phase 1 were dominated by externalizing individual ideas on the GS space. There were few cross-media adjacency events. It could be seen that Group 1's product was mainly composed of inscriptions consisting of individual 
vocabulary or simple phrases; and all the inscriptions were rearranged without discarding any of them, and no coherent logic could be seen clearly. Figure 6 shows the state of Group 1's final group output at the end of Phase 1 .

\section{Prompting notice observed in group 3 at phase 1}

While all the students received the same instructions from the teacher, the way in which Group 3 coordinated group work was different from the way that Group 1 did. Group 1's approach in role assignment seemed more democratic, whereas the approach adopted by Group 3 was relatively dictatorial. Sophia, as the leader of the Group, made a decision without consulting her group members. Her group members might have been used to her style. They accepted Sophia's arrangement and quickly created new GS blank postings in their individual boards and attempted to contribute their own ideas respectively.

As shown in Fig. 7, cross-media adjacency events can be frequently observed even at the beginning of the group work, where prompting notice was the inscriptional device being used. It should be pointed out that "noticing" a form of input must occur to acquire the target language (Swain and Lapkin 1995). In the opinion of some L2 researchers, learners may notice that they do not know how to say or write precisely the meaning they wish to convey while attempting to produce in the target language. When students were asked to brainstorm their ideas on the given topic, and when they had already formed some ideas to convey but did not know how to express in the target language, they would ask for help from their group members. Thus, group understanding can develop in this process. For instance, in the crossmedia adjacency events, $3 \mathrm{~L} 1$ to $3 \mathrm{G} 1(3 \mathrm{~L} 1 \rightarrow 3 \mathrm{G} 1)$, William first asked Sophia how to express "satisfied" in Chinese, but Sophia was unsure herself. Sophia tried to explain the word “satisfied” in a concrete context by saying, ““相貌”什么啊? looks, looks!”. William pointed out that “外表” was more appropriate than “相貌”. At this moment, another group member Ben attempted to join the discussion. As William was about to give up, an idea suddenly occurred to Ben and he responded that "satisfied" means “满意” in Chinese. Both William and Sophia chimed in their agreement. William then wrote down “对自己的外表不满意” (“not satisfied with one's own appearance") and published it onto the public board. The aggregate of each group member's contributions was the construction of language-related knowledge. They co-

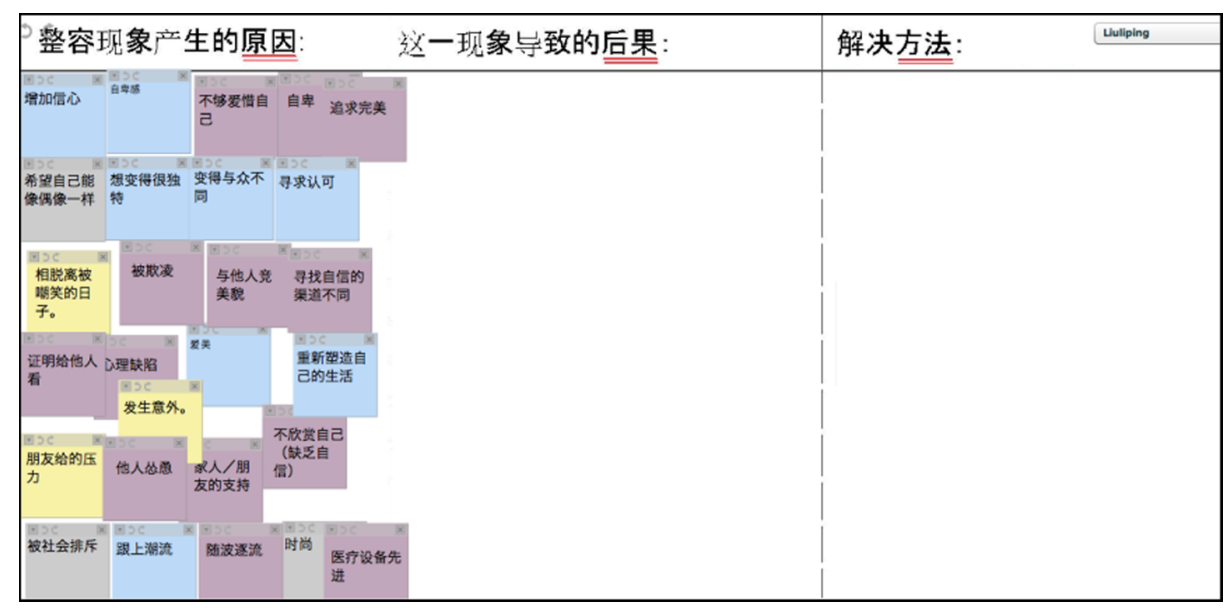

Fig. 6 A screenshot captured from Group 1's public board at the end of Phase 1 
constructed the knowledge because they identified a linguistic problem and they worked together to seek a solution.

The cross-media adjacency events (both $3 \mathrm{~L} 1 \rightarrow 3 \mathrm{G} 1$ and $3 \mathrm{~L} 2 \rightarrow 3 \mathrm{G} 2$ ), shown in this excerpt, explain and demonstrate a new pattern of medium transition: from language-related to GS inscription ( $L A N G \rightarrow G S$ ). Their interactional moves for group-understanding development can be identified as below:

- Asking for help explicitly to complete the text. This happened in a situation in which a student needed to express an idea to start or continue his/her work.

- Collecting informative linguistic knowledge to translate content and reached a consensus once a "correct" answer was given. During this process, students clarified the ideas that they would like to externalize and their understanding of the ideas expressed by others.

- Transforming the idea into an inscription.

The requirement to brainstorm for vocabulary/ideas in the target language on the GS space triggered L2 learners to consciously recognize some of their linguistic problems. In doing so, learners might generate linguistic knowledge that was new for them. In this circumstance, prompting notice is the inscriptional device being used, and face-to-face provided a more convenient channel for communicating and exchanging knowledge.

\section{Promoting synergy observed in group 1 at phase 3}

The third phase of the task was designed to encourage and scaffold students to participate in more intensive and deeper cognitive activity. At this phase, more time was allocated. The students were encouraged to think and to exchange their ideas verbally within the group. In Fig. 8, we see cross-media adjacency events from GS inscription to Content-related talk to GS inscription $(G S \rightarrow C O N T \rightarrow G S)$ happened frequently (e.g., 2G16 $\rightarrow 1 \mathrm{C} 31 \rightarrow 1 \mathrm{G} 48,2 \mathrm{G} 15 \rightarrow$ $1 \mathrm{C} 32 \rightarrow 1 \mathrm{G} 49$, and $2 \mathrm{G} 15 \rightarrow 1 \mathrm{C} 32 \rightarrow 1 \mathrm{G} 50$ ). They helped to explain and demonstrate how the inscriptional device functioned as promoting synergy in productive group-understanding development.

The excerpt starts when Qiqi encouraged her group members to participate in some verbal discussions based on existing postings. Yachne responded positively to Qiqi's request (1R16). The data show that the students made a choice in their usage of the representational tool, and the choice was coordinated through verbal talk. This kind of choice-making and coordination can also be observed in the cross-media responses (e.g., 1R8->2G48).

After the students decided to proceed with their group work, Qiqi led the group to generate an idea based on an inscription from Group 2. When the students in the group had reached a quick consensus on the content, they did it through face-to-face talk (1C31). Yachne was arbitrarily selected (actually, chosen through a game of rock-paper-scissors) to summarize what they just discussed and to render them into texts on GS space (1R8). A group inscription (1G48) was finally published by Yachne on the group's board. It can be seen that the ideas that originated from Qiqi, which were also the ones they had discussed verbally, were integrated by Yachne into the board. For example, when Qiqi mentioned “把他们送去心理医生看” (“send them to the psychiatrists), Yachne found that it was a good idea and could further improve on it, saying “其实可以,可以哎!还有就是让他们上一些培训班,让他们看到自己的优点” (“It is feasible, definitely! Also, send them to some training centers where they can be taught to identify their own strengths”). In the same vein, when Yachne proposed the sentence, “让他们看到自己的优 点” (“Let them identify their own strengths”), Qiqi accepted it and added “他们看到自己的价值” (They can identify their own value). Combining Qiqi's input, Yachne came up with the final 


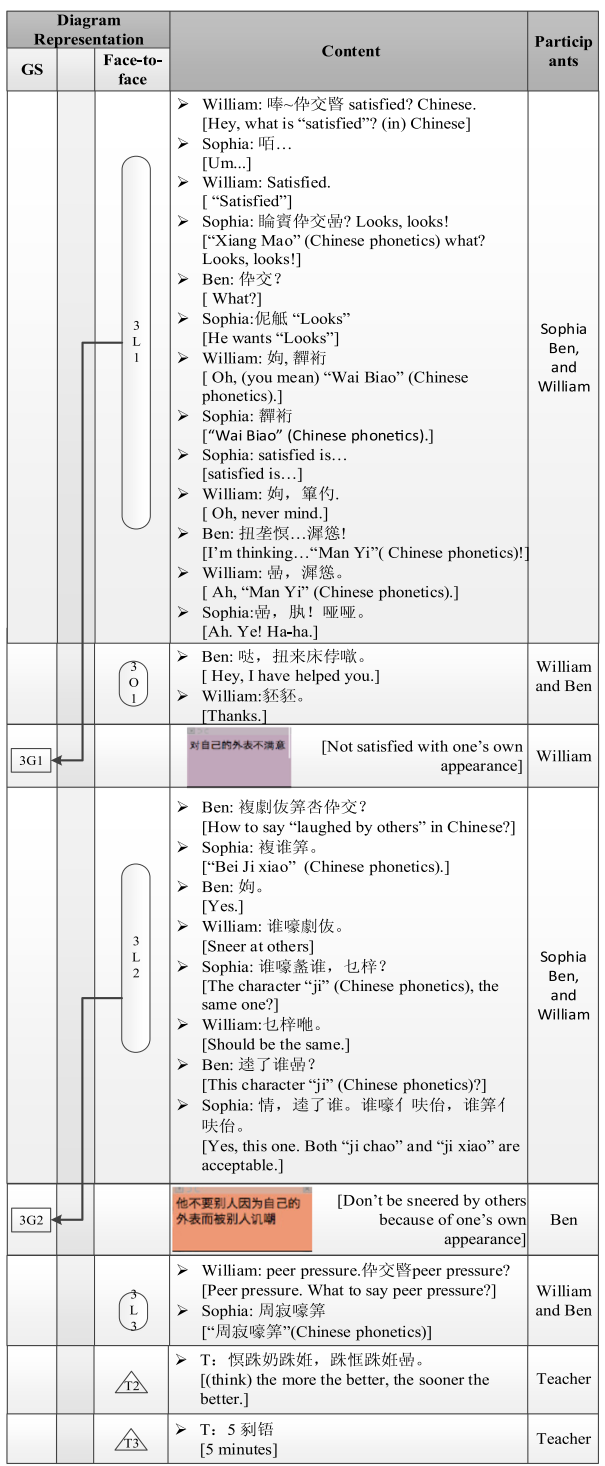

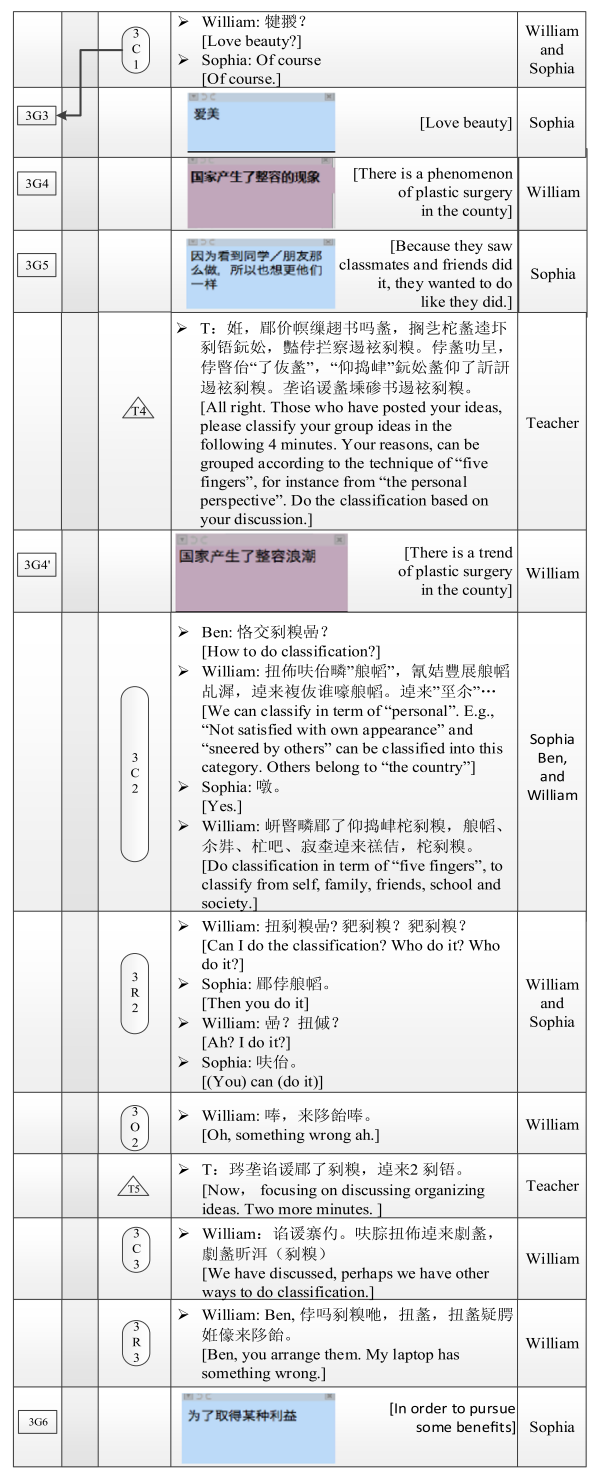

*Note: 3G4' refers to $3 G 4$ re-posted after being edited.

Fig. 7 Excerpt 2: Group 3's interactional events at Phase 1

group inscription with the content “让人们开始了解自己的优势和明白自身的价值” (“Let them be aware of their own strength and value").

We also observed the same type of cross-media adjacency events $(2 \mathrm{G} 15 \rightarrow 1 \mathrm{C} 32 \rightarrow 2 \mathrm{G} 49$ and $2 \mathrm{G} 15 \rightarrow 1 \mathrm{C} 32 \rightarrow 1 \mathrm{G} 50$ ) in this excerpt. Group 1 resumed their content knowledge-related talk based on a posting from Group 2 and contributed a relevant new one. During this period of time, all four students were engaged in the talk. They took turns to seek, interpret, and summarize information, so as to develop their understanding of the topic and work out a new solution. The inscriptional device still functioned to prompt a synergic effect on 


\begin{tabular}{|c|c|c|c|c|}
\hline \multicolumn{2}{|c|}{$\begin{array}{c}\text { Diagram } \\
\text { Representation }\end{array}$} & \multirow{2}{*}{\multicolumn{2}{|c|}{ Content }} & \multirow{2}{*}{$\begin{array}{c}\text { Particip } \\
\text { ants }\end{array}$} \\
\hline \multirow[t]{2}{*}{ GS } & $\begin{array}{c}\text { Face-to- } \\
\text { face }\end{array}$ & & & \\
\hline & $\begin{array}{c}1 \\
\mathrm{R} \\
16\end{array}$ & \multicolumn{2}{|c|}{$\begin{aligned}> & \text { Qiqi: 扭佈冤谄谖 } \\
& \text { [Haven't yet. Let's discuss first.] } \\
> & \text { Yachne: 婎 } \\
& \text { [Ok.] } \\
> & \text { Qiqi: 而且要讲越多，越好。 } \\
& \text { [And the more, the better.] } \\
> & \text { Yachne: 那我们就一张纸，一张纸来。 } \\
& \text { [Then we do the postings one by one.] } \\
> & \text { Qiqi: 我们就慢慢讨论。 } \\
& \text { [Let's discuss. Take it slow.] }\end{aligned}$} & $\begin{array}{l}\text { Qiqi and } \\
\text { Yachne }\end{array}$ \\
\hline & 31 & \multicolumn{2}{|c|}{ 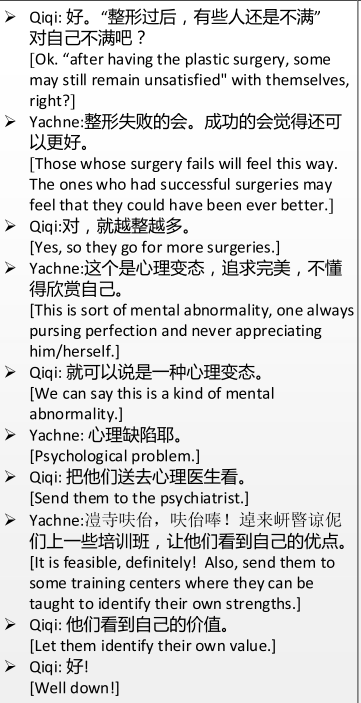 } & $\begin{array}{l}\text { Yachne } \\
\text { and Qiqi }\end{array}$ \\
\hline \multirow[b]{2}{*}{1648} & $\left(\begin{array}{l}1 \\
\mathrm{R} \\
8\end{array}\right.$ & $\begin{array}{l}>\text { Group: Stone, scissor } \\
>\text { Group: Stone, scisso } \\
>\text { Group: Hahaha, Yac }\end{array}$ & $\begin{array}{l}\text { paper } \\
\text { paper } \\
\text { e }\end{array}$ & Group \\
\hline & & $\begin{array}{l}\text { 心理缺陷 : } 1 \text {. 在心理 } \\
\text { 医生、家人、朋友的帮 } \\
\text { 即下, 认知自己的优势 } \\
\text { 和的值。 }\end{array}$ & $\begin{array}{r}\text { [Psychological problem: } \\
1 . \text { with the help of the } \\
\text { psychiatrist, families } \\
\text { and friends, let them be } \\
\text { aware of their own } \\
\text { strength and values.] }\end{array}$ & Yachne \\
\hline
\end{tabular}

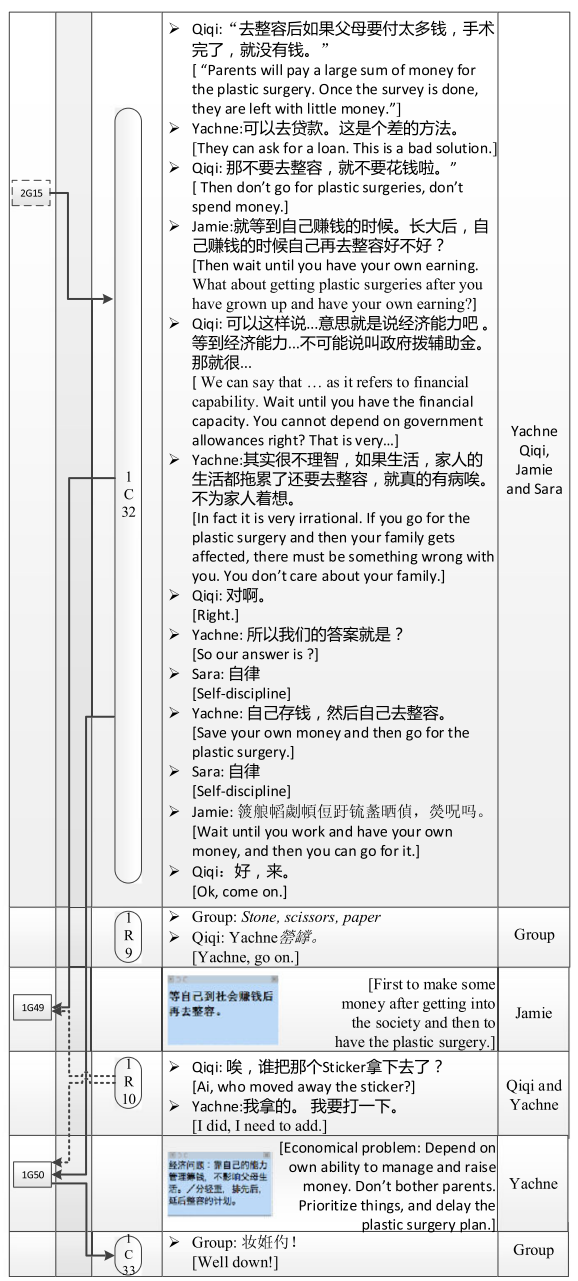

Fig. 8 Excerpt 3: Group 1's interactional events at Phase 3

developing group understanding. For instance, since an existing posting 1G15 mentioned a financial problem, Yachne suggested the phrase “贷款” (“Loan request”). Qiqi considered it inappropriate, as she believed that it was unacceptable to spend money (on plastic surgery) without financial capacity. Then Jamie suggested, “长大后, 自己赚钱的时候自己再去整容好不好” ("What about getting plastic surgeries after you have grown up and have your own earnings?"). This was accepted by Qiqi, and she responded, “可以这样说 ...思就是说经济能力吧 ...” ("We can say that ... as it refers to financial capability ...").

Such a type of cross-media adjacency event seems effective for developing a group understanding on the given topic. However, it has to be pointed out that not all L2 learners can manage it. To foster such an interaction, students are required to possess a certain proficiency in expressing their ideas fluently in the target language. Furthermore, adequate language proficiency can help to summarize and further improve the content as discussed. As observed in the excerpt, Jamie wrote down her idea, which was first expressed verbally, and 
then posted it (1G49). This aroused the attention of Qiqi and Yachne. Yachne was not satisfied with Jamie's posting, so she removed it from the public board and posted a new one. After she has provided a comprehensive summary of what her group just discussed, the new posting (1G50) was quickly accepted by all other group members, including Jamie (1C33). It should be noted that though it was Yachne who finally crafted and published the posting, the posting actually represented the collective knowledge achieved by the group.

Corresponding to this pattern of medium transition, the observable interactional moves in this excerpt are summarized below:

- Reading aloud the written content of an inscription.

- Engaging in verbal discussion during which improper contents or contents that could have been written better were pointed out and new ideas relevant to the original idea were proposed.

- Pooling knowledge to polish the sentences/ideas, and reach a consensus.

- Completing the sentence in GS.

The cross-media adjacency events listed above demonstrate how a group with high language proficiency established and maintained group understandings in completing the planning task in collaborative writing. The students in the group worked together in putting forward and solving the problem iteratively. They worked continuously to achieve a deeper and more comprehensive understanding toward the writing topic through sharing and synthesizing their ideas. Intersubjective meaning making via face-to-face at each interaction cycle was closed or reflected in the creation of a novel inscription. Additionally, it is found that there was little negotiation among the group of students, though elaboration could be found in their interactional moves. That is possibly because the member with higher language proficiency (Yachne) played a more dominant role. This finding is consistent with what Watanabe and Swain (2007) found when they investigated the effects of L2 proficiency on patterns of interaction in dyads in L2 learning.

Different from Group 1, whose Chinese language proficiency was relatively high, Group 3, the group of comparatively poor language proficiency, adopted another approach to coconstructing group inscriptions, but they also produced group inscriptions of good quality. In their group work, language-related knowledge talk interlaced with content-related knowledge talk, and the inscriptional device in this circumstance, functioned as realizing parallels.

\section{Realizing parallels observed in group 3 at phase 3}

The inscriptional device played a role as realizing parallels means that after verbal talk, students worked concurrently to generate GS postings on the basis of the content that they just discussed and confirmed. Excerpt 4 below demonstrates how Group 3 students interacted with one another to complete the sub-task at Phase 3, in which the role of inscriptional devices was realizing parallels (Fig. 9).

As shown in the excerpt, all three students engaged in cognitive activity. It started when Sophia made a less explicit attempt to get the attention of other group members by murmuring, “解决方法” (“the solution”). Ben noticed her actions and responded to her. Ben tried to offer solutions, taking the perspective of the school, but he could not finish the sentence by himself. Following Ben's thinking, Sophia added that in addition to the school, actions taken by the family were necessary to solve the problem. William agreed with Sophia's idea that the family should criticize the ones who intended to go for plastic surgery. He added that apart from only providing criticism, the family should prevent the students from going for plastic surgery. 


\begin{tabular}{|c|c|c|c|}
\hline \multicolumn{2}{|c|}{$\begin{array}{c}\text { Diagram } \\
\text { Representation }\end{array}$} & \multirow{2}{*}{ Content } & \multirow{2}{*}{$\begin{array}{c}\text { Particip } \\
\text { ants }\end{array}$} \\
\hline GS & $\begin{array}{l}\text { Face-to- } \\
\text { face }\end{array}$ & & \\
\hline & $\begin{array}{c}3 \\
\mathrm{C} \\
12\end{array}$ & 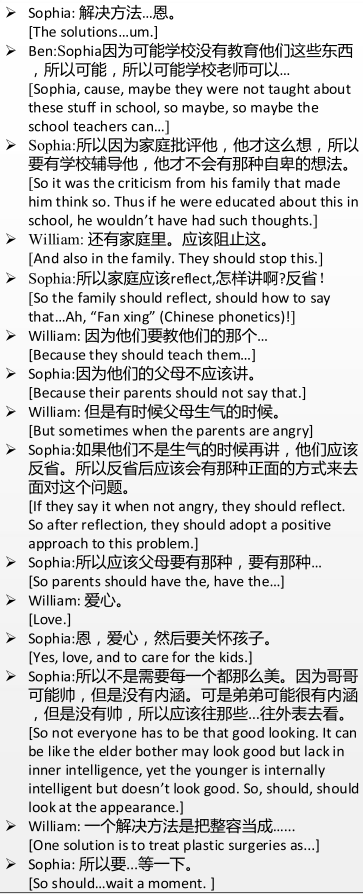 & $\begin{array}{l}\text { William } \\
\text {, Ben, } \\
\text { and } \\
\text { Sophia }\end{array}$ \\
\hline & $\begin{array}{c}5 \\
c \\
19 \\
19\end{array}$ & 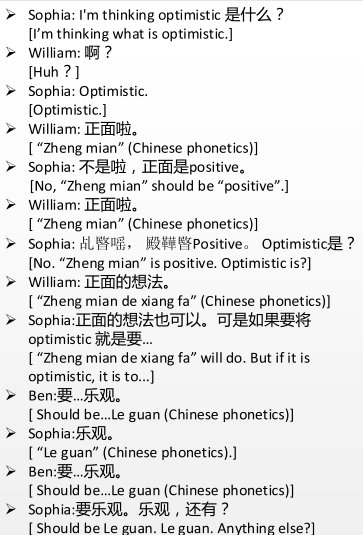 & $\begin{array}{l}\text { William, } \\
\text { Ben, } \\
\text { and } \\
\text { Sophia }\end{array}$ \\
\hline & & $\ldots \ldots .$. & \\
\hline $3 \mathrm{G} 16$ & & 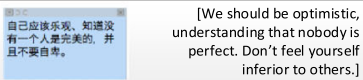 & Sophia \\
\hline
\end{tabular}

\begin{tabular}{|c|c|c|c|}
\hline & $\begin{array}{c}\mathrm{R} \\
12\end{array}$ & $\begin{array}{l}\text { Sophia:所以你写父母，你写学校，我写... } \\
\text { [So you write the "parents" you write the } \\
\text { "school", I write...] }\end{array}$ & Sophia \\
\hline & \multirow{4}{*}{$\begin{array}{l}3 \\
\mathrm{~L} \\
9 \\
\\
\\
\\
\\
3 \\
\mathrm{C} \\
14\end{array}$} & $\begin{array}{l}>\text { Ben:怎么说他们应该教育辅导学生? } \\
\text { 关于整容... } \\
\text { [How to say they should educate the students? } \\
\text { about plastic surgeries...] } \\
\text { Sophia:应该要辅导学生不要让他们往负面的 } \\
\text { 想法去。走去。 } \\
\text { [Should educate the students not to go } \\
\text { negative.] }\end{array}$ & \\
\hline & & $\begin{aligned}> & \text { Ben: 哪个往? } \\
& \text { [Which “"wang” (Chinese phonetics)] } \\
> & \text { Sophia:"往"有两个。 } \\
& \text { [There are two.] } \\
> & \text { Ben: 这个? } \\
& \text { [This one?] } \\
> & \text { Sophia: 恩。 } \\
& \text { [Yes.] } \\
> & \text { Ben: 不要有负面的想法。 } \\
& \text { [Don't have negative thoughts.] } \\
> & \text { Sophia: 恩。 } \\
& \text { [Yes.] }\end{aligned}$ & $\begin{array}{l}\text { Ben and } \\
\text { Sophia }\end{array}$ \\
\hline & & \begin{tabular}{|l}
$>$ Ben: 父母可以安心地把孩子送学校... \\
[Parents won't be worried when sending the \\
kids to school.] \\
$>$ Sophia: 并且加强，并且...并且...呃...How to \\
say... \\
[And emphasize, and....and...Eh....How to say...] \\
$>$ Ben: Confidence? \\
[Confidence?] \\
$>$ Sophia: 不是。应该 emphasize。 \\
[No. It should be "emphasize".]
\end{tabular} & $\begin{array}{l}\text { Sophia, } \\
\text { Ben and } \\
\text { William }\end{array}$ \\
\hline & & 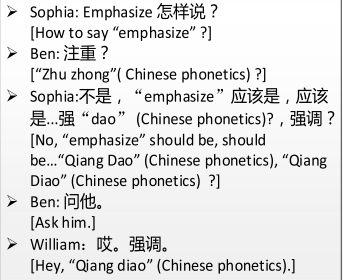 & $\begin{array}{l}\text { Ben, } \\
\text { Sophia } \\
\text { and } \\
\text { William }\end{array}$ \\
\hline & \begin{tabular}{c|}
3 \\
$\mathrm{C}$ \\
15
\end{tabular} & $\begin{aligned}> & \text { William: 哎, Sophia , 那个家庭... } \\
& {[\text { Hey, Sophia, the family...] }} \\
> & \text { Sophia: 他们的好... } \\
& {[\text { Their good...] }} \\
> & \text { William: 优点。 } \\
& \text { [Strengths.] } \\
> & \text { Sophia: 优点。 } \\
& \text { [Strengths.] }\end{aligned}$ & $\begin{array}{l}\text { Ben and } \\
\text { Sophia }\end{array}$ \\
\hline 3G14 & & 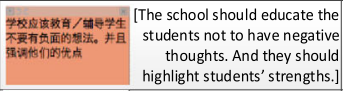 & Ben \\
\hline $3 \mathrm{G} 15$ & & 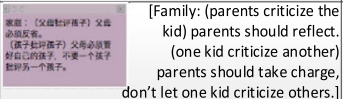 & William \\
\hline
\end{tabular}

Fig. 9 Excerpt 4: Group 3's interactional events at Phase 3

Sophia tried to find a more appropriate word to express what the family should do. She thought of the word "reflect" in English but initially she did not know how to express it in Chinese. William tried to help Sophia, but he was interrupted by Sophia when she thought of how to express "reflect" in Chinese on her own. 
When William questioned the validity of Sophia's statement, Sophia further explained what she would like to say. Meanwhile a new idea occurred to her. This time, she could not express the idea clearly and fluently. William helped her complete the sentence, which was accepted by Sophia. Then Sophia tried to provide a concrete example to explain "appearance is not the most important determinant." The idea was good per se, but her expression was not very clear. William suggested to Sophia to contribute some ideas from the "perspective of individuals". Sophia agreed with William's suggestion and began to further elaborate her own thinking. When William tried to summarize her ideas, he was interrupted by Sophia again. Sophia switched the discussion from content knowledge to linguistic knowledge. She tried to express "optimistic" in Chinese. William tried to help her, but his answer failed to satisfy her. Ben offered another one, and that one was accepted by Sophia. After that, Sophia tried to resume their content-related discussion by asking, "Anything else?"

During this excerpt, Sophia's dominant role in the verbal discussion was quite obvious. She interrupted when others were speaking, and she changed the subject of discussion several times. Yet the whole discussion process still seemed effective. It then continued with iteratively questioning, explanation, and interpretation.

\section{Summary of results}

The empirical data in this study shows that even under the same teacher's instruction, different small groups evolved alternative approaches to carry out the given tasks using GS. The results indicated that group language proficiency restricted L2 learners' involvement in verbal talk. Groups with higher language proficiency tended to focus more on content-related knowledge talk than on language-related knowledge talk. Yet the influence of group language competency on their involvement in online interactions was not so apparent.

Beyond the understanding that the representational tool served as an external shared space where small groups kept a record of shared thinking (Suthers and Hundhausen 2003), the role of inscriptional devices in group-understanding development was further identified and demonstrated through the qualitative micro-analysis of the interactions. The findings revealed the fabric of common ground in a classroom environment with representational tools. According to our data, when the inscriptional device functioned as referencing or pinpointing, the corresponding interactional moves were comparatively less cognitively demanding. In contrast, when the role of inscriptional devices functioned as promoting synergy, realizing parallels, or prompting notice, the corresponding interactional moves were more cognitively demanding and more productive group interactions occurred, because students engaged in searching for information, explaining, elaborating, and summarizing. It has been widely reported in educational literature that such cognitive engagement requiring higher-order-thinking skills is critical to meaningful learning (e.g., Zhu 2006). Nevertheless, as observed, it was not always the case that groups with higher language proficiency drew more frequently upon the inscriptional device for promoting synergy, realizing parallels, or prompting notice in group meaning making.

The findings suggested that in the context of a collaborative L2 writing task, students were able to constantly improve their understanding on the writing topic through group interactions, regardless of their language proficiency. Groups with high language proficiency focused more on the writing content, whereas groups with low language proficiency spent more time and effort on language-related talk to ensure the accuracy and appropriateness of the creation of group inscriptions. This finding is consistent with our quantitative data, in which more language-related problems emerged (and needed to be solved), as students with lower language proficiency use the target language to externalize their thinking or to internalize information brought forward by others. 
Theories of second language learning (e.g., the Noticing Hypothesis from Schmidt 1990, and the Output Hypothesis from Swain 1985) have emphasized that the learner's attention to language as an object while engaged in communication is beneficial for L2 learning. Two patterns of medium transition relating to language-related talk and their effects on a small group's L2 development were distinguished in this study. Corresponding to the pattern of medium transition-LANG $\rightarrow \mathrm{GS}$ - the role of inscriptional devices in group-understanding development was prompting notice. The activity of producing the target language on the GS space prompted students to consciously recognize some of their linguistic problems, and this triggered cognitive processes in which group members co-constructed or consolidated their existing linguistic knowledge and created a new posting that was accepted by all of them. Corresponding to the pattern of medium transition- $\mathrm{GS} \rightarrow \mathrm{LANG}-$ the inscriptional device functioned as pinpointing, which had an emphasis on prompting individuals to inquire about the pronunciation or meaning of specific characters/phrases on the posting. Since no subsequent improvement or creation of a new group inscription could be observed in this pattern, it was difficult to judge whether the mutual understanding was successfully established by all group members. In other words, when the role of inscriptional devices functions as pinpointing, group meaning making can be observed but its effectiveness cannot be guaranteed.

The qualitative micro-analysis of interactions also reveal that language-related talk often intertwined with content-related talk, especially in the group with relatively low language proficiency. Once verbal talk went beyond language-related knowledge, the talk would not be dominated by the authoritative group members, and hence all the members could have comparatively equal opportunities to contribute to their group work. Instead of solely compensating for deficient language-related knowledge, students constantly ventured new ideas and updated their common ground. In such a process, more language-related problems might emerge as well. Along with this, they effectively constructed and consolidated understanding of both content-related knowledge (including understanding of the given topic and the writing strategy) and language-related knowledge.

The data drawn from cross-media adjacency events also indicate that the role of inscriptional devices was task sensitive. For example, in Phase 1 of the task, the students were encouraged to provide their own ideas in an initial text. In doing so, the inscriptional device mainly functioned as referencing or pinpointing. At the final phase of the task, however, the students were required to discuss with one another, modify existing inscriptions and create truly shared group inscriptions as products of their collaborations. Even though different small groups still appropriated GS in different ways, the inscriptional device functioned more as promoting synergy, realizing parallels, or prompting notice in more productive group meaning making in both Group 1 and Group 3. Thus, there was not just one way to utilize the tool to perform the task, and the students decided by themselves how to bring the tool into use to complete the given task.

\section{Discussion}

Studying whether and how a representational tool can be used for facilitating collaborative language learning requires us to look into the learning process of how the tool is brought into use, or rather how it is attuned to, interacted with, and shaped in various and varied practices (Overdijk et al. 2012). DeSanctis and Poole (1994) described how groups in organizations bring technology into action through appropriation of rules and resources that are provided by the technology. According to them, "new social structures emerge in group interaction as the 
rules and resources of the technology are appropriated in a given context and reproduced in group interaction over time" (DeSanctis and Poole 1994, p. 129). Following this line of reasoning, researchers (e.g., Oliver 2011; Overdijk et al. 2012) argued that the rationale of shaping collaborative interactions underlying a part of CSCL research should be replaced by a rationale of mutual shaping of human agent and technical artifacts, which posits that "the technical artifact shapes the learner's behavior, and that the learner shapes the technical artifact — or rather, the opportunities that are made available by it" (Overdijk et al. 2012, p. 207).

The initial rationale of shaping collaborative interactions may suggest that the effects of a technical artifact on collaboration could be predicted rather straightforwardly and that learners could readily engage in more productive interactions (Overdijk et al. 2012). However, an inscriptional device can be appropriated in unexpected ways (Medina and Suthers 2012), enactment of a script is always to some extent unpredictable (Dillenbourg and Tchounikine 2007; Dillenbourg et al. 2009), and productive integration of CSCL technologies as instruments of learning and instruction is a developmental process (Ritella and Hakkarainen 2012). It is important to investigate how technological artifacts are brought into use by participants who are facilitating collaborative activity interactively, and how group accomplishment is contextually situated. Instead of one-shot experiments in which teachers and students have to learn both novel pedagogy and a new collaborative technology, sustained iterative and expansive efforts of cultivating shared practices are required for designing and investigating new learning spaces for the future (Ritella and Hakkarainen 2012; Hämäläinen and Oksanen 2013).

Situated in a setting of L2 learning, this study focused on investigating the mutual shaping of technology in the classroom at the level of the small group. A major concern of this study was to examine how small-group task completion is contingent on cross-media interactions, and to explore the temporal scope of this contingency as mediated by persistent inscriptions. The case was selected and investigated when the participants had truly gone through the expansive learning that is required for cultivation of novel computer-mediated collaborative practices of working creatively with knowledge for a whole year. Ultimately, it helped to deepen the understanding of participants' appropriation of technological resources, which can help to trigger meaningful pedagogical uses of the technology but has not yet been sufficiently addressed (Ritella and Hakkarainen 2012).

Our study explored several connections between medium transition and the trajectory of group-understanding development, which we investigated through cross-media adjacency events. The results indicated that using the representational tool-GS in L2 classrooms - is beneficial for collaborative language learning. Empirical data evidenced that different small groups evolved alternative approaches in carrying out the tasks; group language competency as well as task design influenced the way in which the representational tool was appropriated. The inscriptional device had significant effects on the students' interactions and had different influences on group-understanding development. Stated succinctly, this study provided empirical data to illustrate some of the mutual influences between the tool and the users in small groups.

Our findings about the appropriations of the representational tool in completing L2 collaborative writing tasks and the inscriptional devices in group-understanding development highlight a number of beneficial features of the representational tool supplementing rather than substituting face-to-face communication within a single language learning class. Here we need not elaborate any further on the obvious advantages of online representational effects on enlarging the bandwidth of resource sharing, compared to the traditional use of pen and paper (e.g., the convenience of intergroup interaction without physical movement). The beneficial features of the online representational tool are elaborated by emphasizing its complementary role in the improvement of L2 learning in a classroom environment. 
First, online interaction tends to feature more balanced participation than face-to-face discussion. When online interaction is juxtaposed with face-to-face interaction, students with higher language proficiency are less likely to dominate the group work. The observations in this study indicate that all small groups, regardless of their language proficiency, were willing to externalize their ideas or help improve postings from others, whereas group language proficiency restricted their involvement in verbal talk, especially when asked to communicate in the target language. This result is consistent with the literature on computer-assisted language learning which shows that L2 learners tend to participate more equally and take more risks to experiment with ideas (i.e., try more creative ideas) in online environments than in traditional face-to-face classroom environments (e.g., Meunier 1998; Warschauer 1997).

Second, embedding representational tools in classroom learning empowers students to notice their linguistic problems and incorporate knowledge from others to solve problems. Meanwhile, the shared space for the co-construction of group output (inscriptions) gives way to discussion about (and justifications of) representational acts as well as inducing knowledge sharing. Our results indicated that the activity of producing inscriptions in the target language prompted students to consciously identify gaps in their own knowledge, and this triggered cognitive processes in which group members co-constructed or consolidated their existing linguistic knowledge and generated a new posting that was accepted by all of them through verbal discussion (e.g., in the pattern of medium transition $\mathrm{LANG} \rightarrow \mathrm{GS}$, the inscriptional devices functioning as prompting notice). Therefore, in the context of language learning, the co-construction of inscriptions can be deemed as "writing to learn" (Williams 2012), which promotes learning content knowledge as well as knowledge about the language (Hirvela 1999). Previous literature has found that, compared to other forms of language use, a written record pushes learners to demand greater precision, which may encourage them to consult their explicit knowledge (Williams 2012).

Third, the contributed inscription reminds participants of previous ideas and initiates elaboration or negotiation on them, and possibly serves as a resource for the emergence of new ideas/ perspectives. In this case study, we saw the high occurrence of the medium transition from GS inscriptions to face-to-face discussions, and some of them were accompanied by the creation of new GS inscriptions. The qualitative micro-analysis of interaction has suggested that group understanding develops productively in the pattern of medium transition - GS $\rightarrow$ CONT $\rightarrow$ GS - where the inscriptional device plays a role as promoting synergy. In semiotic terms, the inscriptions are representations not by reference to fixed concepts but by being in contextually defined relations to the situation at hand (Goodwin 2003). Therefore, it is explained that the persistent inscription providing semiotic resource evokes and facilitates subsequent negotiations of meaning (Medina and Suthers 2012; Suthers and Hundhausen 2003).

All in all, the results of the study add to a growing research indicating the effects of representational tools on learning. Exploring and understanding the specific functions of inscriptional devices in depth and in situ help us reflect on some of the practical implications of the findings and the discussion above for suggesting pedagogical design improvements by integrating a representational tool such as GS to promote language learning. The pedagogical design-including three gradual steps: externalizing, building upon, and pursuing consensus - has been proven effective in this study. It has been evidenced that dividing the complex collaborative writing process into step-by-step tasks within the students' reach enables all the students to participate, make their knowledge of writing explicit, and develop group inscriptions that cannot be authorized by one student. This study reiterates the position that writing is not simply another way of practicing grammar and that a collaborative L2 writing activity should be designed to scaffold students to exchange and negotiate content knowledge rather than compensate for their deficits in linguistic knowledge. 


\section{Conclusion}

In this study, we investigated how small groups of students appropriate a representational tool for facilitating collaborative L2 learning in authentic classrooms. Following the notion of mutual shaping of participants and technical devices (Overdijk et al. 2012), the study has provided empirical data in a case study to demonstrate that small-group L2 learning efficacy while using a representational tool varies due to group language proficiency and task design/ scripts. Based on our analysis of the empirical data, we concluded that there are five functions that the inscriptional device (e.g., a posting on a representational tool space) can play in L2 classroom learning. They are (1) referencing, (2) pinpointing, (3) prompting notice, (4) realizing parallels, and (5) promoting synergy. Concerning the role of the inscriptional device in groupunderstanding development, we argued that several affordances of the representational tool supplement face-to-face communication by emphasizing their complementary role in the improvement of L2 learning in the classroom environment. They are (1) providing opportunities for equal participation (e.g., the inscriptional device functions as accumulating or realizing parallels); (2) empowering L2 learners to be aware of their language problems and to collaboratively solve them (e.g., the inscriptional device functions as prompting notice); (3) serving as resources for the emergence of new idea/perspective (e.g., the inscriptional device functions as referencing, pinpointing, and promoting synergy). It is intriguing that the results of this study cannot be attributed directly to the intervention of task design or the technology per se. The implication is that both software designers and instructional designers need to recognize the intertwining relationships between inscriptional devices and collaborative language learning.

However, the scope of this study is limited to the examination of interactions that occurred among a single class of small groups of students in a networked collaborative writing lesson. As a result, the major limitation of the study is about the generalizability of the findings. Since the results are essentially supported by the analysis of a single case, they offer no grounds for establishing generalizable findings. In order to generalize the findings, there is a necessity to examine the appropriation of the representational tool in other lessons, with diverse task designs. This case study does not aim at predicting that all the identified functions will be played out in all the representational tool-supported L2 learning contexts but rather suggests that teachers and researchers should create conditions that enable the inscriptional device to facilitate more productive group interactions (e.g., promoting synergy).

Since the role of the teacher is also a primary concern of CSCL research, future studies might pay attention to situations where groups with real-time teacher instruction will come up with productive interactions similar to those interpreted in this study. We are now one step nearer to understanding the interplay between multimedia interaction processes and effective collaborative learning, especially in the context of language learning where language per se is not only the medium but also the content of learning. However, in order to address this question better, researchers will be required to exam the essential purpose of L2 learning per se. With the common knowledge of the beneficial features of using the generic representational tool in classroom L2 learning, more researchers from different interdisciplinary backgrounds (e.g., applied linguistics or second language acquisition) are expected to join and work together to better design task scripts and, thus, further unlock the efficacy of pedagogical innovation of CSCL in language learning.

Acknowledgments This paper is based on the first author's PhD study in NIE (National Institute of Education, Singapore) and finished in her postdoctoral period at CHILI Lab in EPFL (École polytechnique fédérale de Lausanne, Switzerland). The authors are very grateful to the teacher and the students from SST (School of Science and Technology, Singapore) for their participation in the study reported in this paper. We would also like to thank Luis P. Prieto for his constructive comments on the paper. 


\section{References}

Baker, M., Andriessen, J., Lund, K., van Amelsvoort, M., \& Quignard, M. (2007). Rainbow: A framework for analyzing computer-mediated pedagogical debates. International Journal of Computer Supported Collaborative Learning, 2, 315-357.

Bera, S., \& Liu, M. (2006). Cognitive tools, individual differences, and group processing as mediating factors in a hypermedia environment. Computers in Human Behavior, 22, 295-319.

Blake, R., Wilson, N. L., Cetto, M., \& Ballester, C. P. (2008). Measuring oral proficiency in distance, face-toface, and blended classrooms. Language Learning \& Technology, 12(3), 114-127.

Brodahl, C., Hadjerrouit, S., \& Hansen, N. K. (2011). Collaborative writing with web 2.0 technologies: Education students' perceptions. Journal of Information Technology Education, 10, 73-104.

Cakir, M. P., Zemel, A., \& Stahl, G. (2009). The joint organization of interaction within a multimodal CSCL medium. International Journal of Computer-Supported Collaborative Learning, 4, 115-149.

Chai, C. (2006). Writing plan quality: Relevance to writing scores. Assessing Writing, 11, 198-223.

Chen, W., Looi, C. K., \& Tan, S. (2010). What do students do in a F2F CSCL classroom? The optimization of multiple communications modes. Computers in Education, 55, 1159-1170.

DeSanctis, G., \& Poole, M. S. (1994). Capturing the complexity of advanced technology use: Adaptive structuration theory. Organization Science, 5(2), 121-147.

Dillenbourg, P., \& Tchounikine, P. (2007). Flexibility in macro-scripts for computer-supported collaborative learning. Journal of Computer Assisted Learning, 23, 1-13.

Dillenbourg, P., \& Traum, D. (2006). Sharing solutions: Persistence and grounding in multi-modal collaborative problem solving. The Journal of the Learning Sciences, 15(1), 121-151.

Dillenbourg, P., Järvelä, S., \& Fischer, F. (2009). The evolution of research on computer-supported collaborative learning: From design to orchestration. In N. Balacheff et al. (Eds.), Technology-enhanced learning (pp. 319). Dordrecht: Springer Verlag.

Dooly, M. (2011). Divergent perceptions of telecollaborative language learning tasks: Task-as-workplan vs. taskas-process. Language Learning \& Technology, 15(2), 69-91.

Dwyer, N., \& Suthers, D. D. (2006). Consistent practices in artifact-mediated collaboration. Computer-Supported Collaborative Learning, 1, 481-511.

Dyke, G., Lund, K., Jeong, H., Medina, et al. (2011). Technological affordance for productive multivocality in analysis. In H. Spada et al. (Eds.), Proceedings of the 9th International Conference on CSCL (pp. 454 463). Hong Kong: International Society of the Learning Sciences.

Elen, J., \& Clarebout, G. (2007). Supporting learning: Increasing complexity? Computers in Human Behavior, $23,1162-1166$.

Elola, I., \& Oskoz, A. (2010). Collaborative writing: Fostering foreign language and writing conventions development. Language, Learning and Technology, 14(3), 51-71.

Enyedy, N. (2005). Inventing mapping: Creating cultural forms to solve collective problems. Cognition and Instruction, 23(4), 427-466.

Firth, A., \& Wagner, J. (1997). On discourse, communication, and (some) fundamental concepts in SLA research. The Modern Language Journal, 81, 285-300.

Fischer, F., \& Mandl, H. (2005). Knowlege covergence in computer-supported collaborative learning: The role of external representation tools. The Journal of the Learning Sciences, 14(3), 405-441.

Fischer, F., Bruhn, J., Gräsel, C., \& Mandl, H. (2002). Fostering collaborative knowledge construction with visualization tools. Learning and Instruction, 12, 213-232.

Gaver, W. W. (1991). Technology affordances. In Proceedings of CHI'91 (pp. 79-84). New York: ACM.

Gibson, J. J. (1979). The ecological approach to visual perception. Boston: Houghton Mifflin.

Gillies, R. M. (2006). Teachers' and students' verbal behaviors during cooperative and small-group learning. British Journal of Educational Psychology, 76, 271-287.

Goodwin, C. (2003). Pointing as situated practice. In S. Kita (Ed.), Pointing: Where language, culture and cognition meet (pp. 217-241). Mahwah: Erlbaum.

Goos, M., Galbraith, P., \& Renshaw, P. (2002). Socially mediated metacognition: Creating collaborative zones of proximal development in small group problem solving. Educational Studies in Mathematics, 49, $193-223$.

Hakkarainen, K. (2009). A knowledge-practice perspective on technology-mediated learning. Journal of Computer-Supported Collaborative Learning, 4, 213-231.

Hämäläinen, R., \& Oksanen, K. (2013). Collaborative 3D learning games for future learning: Teachers' instructional practices to enhance shared knowledge construction among students. Technology, Pedagogy and Education, 3, 1-21.

Hartup, W. W. (1996). The company they keep: Friendships and their developmental significance. Child Development, 67, 1-13. 
Hirvela, A. (1999). Collaborative writing instruction and communities of readers and writes. TESOL Journal, $8(2), 7-12$.

Hmelo-Silver, C. E., Liu, L., \& Jordan, R. (2009). Visual representation of a multidimensional coding scheme for understanding technology-mediated learning about complex natural systems. Research and Practice in Technology Enhanced Learning, 4(3), 253-280.

Hmelo-Silver, C. E., Jordan, R., Liu, L., \& Chernobilsky, E. (2011). Representational tools for understanding complex computer-supported collaborative learning environments. In S. Puntambekar, G. Erkens, \& C. Hmelo-Silver (Eds.), Analyzing interactions in CSCL: Methods, approaches and issues (pp. 83-106). New York, NY: Springer.

Hogan, K., Nastasi, B., \& Pressley, M. (2000). Discourse patterns and collaborative scientific reasoning in peer and teacher-guided discussions. Cognition and Instruction, 17(4), 379-432.

Hwang, G.-J., Kuo, F.-R., Chen, N.-S., \& Ho, H.-J. (2014). Effects of an integrated concept mapping and webbased problem-solving approach on students' learning achievements, perceptions and cognitive loads. Computers in Education, 71, 77-86.

Janssen, J., Erkens, G., Kirschner, P. A., \& Kanselaar, G. (2008). Effects of representational guidance during computer-supported collaborative learning. Instructional Science, 38, 59-88.

Jeong, H. (2013). Verbal data analysis for understanding interactions. In C. Hmelo-Silver, A. M. O’Donnell, C. Chan, \& C. Chinn (Eds.), The international handbook of collaborative learning. London: Taylor and Francis.

Kozma, R. (2003). The material features of multiple representations and their cognitive and social affordances for science understanding. Learning and Instruction, 13(2), 205-226.

Larusson, J. A., \& Alterman, R. (2007). Tracking online collaborative work as representational practice: Analysis and tool. In the 3rd International Conference on Communities and Technologies, Michigan State University, East Lansing, Michigan.

Lingnau, A., Hoppe, H. U., \& Mannhaupt, G. (2003). Computer supported collaborative writing in an early learning classroom. Journal of Computer Assisted Learning, 19(2), 186-194.

Liu, P. L. (2011). A study on the use of computerized concept mapping to assist ESL learners' writing. Computers in Education, 57, 2548-2558.

Liu, C. C., \& Kao, L. C. (2007). Do handheld devices facilitate face-to-face collaboration? Handheld devices with large shared display groupware to facilitate group interactions. Journal of Computer Assisted Learning, 23(4), 285-299.

Looi, C. K., Chen, W., \& Wen, Y. (2009). Exploring interactional moves in a CSCL environment for Chinese language learning. In C. O’Malley, D. Suthers, P. Reimann, \& A. Dimitracopoulou (Eds.), International conference on computer-supported collaborative learning (pp. 350-359). Rhodes Island: ISLS.

Looi, C. K., Chen, W., \& Ng, F. K. (2010). Collaborative activities enabled by GroupScribbles(GS): An exploratory study of learning effectiveness. Computers in Education, 54(1), 14-26.

Looi, C. K., Song, Y. J., Wen, Y., \& Chen, W. L. (2013). Identifying pivotal contributions for group progressive inquiry in a multimodal interaction environment. In D. D. Suthers et al. (Eds.), Productive multivocality in the analysis of group interactions, computer-supported collaborative learning series 16. Springer Science+ Business Media: New York.

McDonough, K., \& Sunitham, W. (2009). Collaborative dialogue between Thai EFL learners during self-access computer activities. TESOL Quarterly, 43(2), 231-255.

Medina, R., \& Suthers, D. D. (2008). Bringing representational practice from log to light. In P. A. Kirschner, F. Prins, V. Jonker, \& G. Kanselaar (Eds.), International Perspectives in the Learning Sciences: Creating a Learning World: Proceedings of the Eighth International Conference for the Learning Sciences (ICLS 2008) (Vol. 2, pp. 59-66). Utrecht: International Society of the Learning Sciences.

Medina, R., \& Suthers, D. (2012). Inscriptions becoming representations in representational practices. Journal of Learning Sciences, 22, 33-69.

Mercer, N. (2005). Sociocuitural discourse analysis: Analysing classroom talk as a social mode of thinking. Journal of Applied Linguistics, 1, 137-168.

Mercer, N. (2008). The seeds of time: Why classroom dialogue needs a temporal analysis. The Journal of the Learning Sciences, 17, 33-59.

Meunier, L. E. (1998). Personality and motivational factors in computer-mediated foreign language communication. In J. A. Muyskens (Ed.), New ways of learning and teaching: Focus on technology and foreign language instruction (pp. 145-197). Boston: Heinle \& Heinle.

Oliver, M. (2011). Technological determinism in educational technology research: Some alternative ways of thinking about the relationship between learning and technology. Journal of Computer Assisted Learning, $27,373-384$.

Onrubia, J., \& Engel, A. (2012). The role of teacher assistance on the effects of a macro-script in collaborative writing tasks. International Journal of Computer Supported Collaborative Learning, 7, 161-186.

Ortega, L. (2012). Epilogue: Exploring L2 writing -SLA interfaces. Journal of Second Language Writing, 21, $404-415$. 
Overdijk, M., \& van Diggelen, W. (2008). Appropriation of a shared workspace: Organizing principles and their application. International Journal of Computer-Supported Collaborative Learning, 3, 165-192.

Overdijk, M., van Diggelen, W., Kirschner, P. A., \& Baker, M. (2012). Connecting agents and artifacts in CSCL: Towards a rationale of mutual shaping. International Journal of Computer-Supported Collaborative Learning, 7(2), 193-210.

Overdijk, M., Diggelen, W. V., Andriessen, J., \& Kirschner, P. A. (2014). How to bring a technical artifact into use: A micro-developmental perspective. International Journal of Computer Supported Collaborative Learning, 9(3), 283-303.

Pakir, A. (1991). The range and depth of English-knowing bilinguals in Singapore. World Englishes, 10, $167-$ 179.

Puntambekar, S., Erkens, G., \& Hmelo-Silver, C. E. (2011). Introduction. In S. Puntambekar, G. Erkens, \& C. E. Hmelo-Silver (Eds.), Analyzing interactions in CSCL (pp. ix-xiv). New York: Springer.

Ritella, G., \& Hakkarainen, K. (2012). Instrumental genesis in technology-mediated learning: From double stimulation to expansive knowledge practices. International Journal of Computer-Supported Collaborative Learning, 7, 239-258.

Roschelle, J. (1994). Designing for cognitive communication: Epistemic fidelity or mediating collaborative inquiry? The Arachnet Electronic Journal of Virtual Culture, 2(2).

Roschelle, J., Tatar, D., Chaudhury, S. R., Dimitriadis, Y., Patton, C., \& DiGiano, C. (2007). Ink, improvisation, and interactive engagement: Learning with tablets. Computer, 40(9), 38-44.

Schmidt, R. (1990). The role of consciousness in second language learning. Applied Linguistics, 11, 192-196.

Shaw, R. S. (2010). A study of learning performance of e-learning materials design with knowledge maps. Computers in Education, 54, 253-264.

Shehadeh, A. (2011). Effects and student perceptions of collaborative writing in L2. Journal of Second Language Writing, 20, 286-305.

Slof, B., Erkens, G., Kirschner, P. A., Janssen, J., \& Phielix, C. (2010). Fostering complex learning-task performance through scripting student use of computer supported representational tools. Computes \& Education, 55, 1707-1720.

Song, Y. J., \& Looi, C. K. (2012). Linking teacher beliefs, practices and student inquiry-based learning in a CSCL environment: A tale of two teachers. International Journal of Computer-Supported Collaborative Learning, 7(1), 129-159.

Stahl, G. (2006). Supporting group cognition in an online math community: A cognitive tool for small-group referencing in text chat. Journal of Educational Computing Research, 35(2), 103-122.

Stahl, G., \& Hesse, F. (2010). The CSCL field matures. International Journal of Computer-Supported Collaborative Learning, 5, 1-3.

Storch, N. (2005). Collaborative writing: Product, process, and students' reflections. Journal of Second Language Writing, 14(3), 153-173.

Stull, A. T., \& Mayer, R. E. (2007). Learning by doing versus learning by viewing: Three experimental comparisons of learner-generated versus author-provided graphic organizers. Journal of Educational Psychology, 99, 808-820.

Suthers, D. D. (2006). A Qualitative analysis of collaborative knowledge construction through shared representations. Research and Practice in Technology Enhanced Learning, 1(2), 115-142.

Suthers, D. D., \& Hundhausen, C. D. (2003). An experimental study of the effects of representational guidance on collaborative learning processes. Journal of Learning Sciences, 12(2), 183-218.

Suthers, D. D., \& Rosen, D. (2011). A unified framework for multi-level analysis of distributed learning. In B. Alberta (Ed.), Proceedings of the 1st International Conference on Learning Analytics and Knowledge (pp. 64-74). NY: ACM New York.

Suthers, D. D., Girardeau, L., \& Hundhausen, C. (2003). Deictic Roles of External Representations in Face-toface and Online Collaboration. In B. Wasson, S. Ludvigsen, \& U. Hoppe (Eds.), Proceedings of the International Conference on CSCL 2003 (pp. 173-182). Dordrecht: Kluwer Academic Publisher.

Suthers, D. D., Dwyer, N., Medina, R., \& Vatrapu, R. (2007). A framework for eclectic analysis of collaborative interaction. In Proceedings of the Computer Supported Collaborative Learning (CSCL) Conference 2007, New Brunswick: International Society of the Learning Sciences.

Suthers, D. D., Dwyer, N., \& Medina, R. (2010). A framework for conceptualizing, representing, and analyzing distributed interaction. International Journal of Computer-Supported Collaborative Learning, 5, 5-42.

Suthers, D. D., Lund, K., Rosé, C., Dyke, G., et al. (2011). Towards productive multivocality in the analysis of collaborative learning. In H. Spada, et al. (Eds.), International Conference on CSCL 2011 (pp. 1015-1022). Hong Kong.

Swain, M. (1985). Communicative competence: Some roles of comprehensible input and comprehensive output in its development. In S. Gass \& C. Madden (Eds.), Input in second language acquisition (pp. 235-253). Rowley, MA: Newbury House. 
Swain, M. (2000). The output hypothesis and beyond: Mediating acquisition through collaborative dialogue. In J. Lantolf (Ed.), Sociocultural theory and second language acquisition (pp. 97-114). Oxford: Oxford University Press.

Swain, M., \& Lapkin, S. (1995). Problems in output and the cognitive processes they generate: A step towards second language learning. Applied Linguistics, 16, 371-391.

Swain, M., \& Lapkin, S. (1998). Interaction and second language learning: Two adolescent French immersion students working together. The Modern Language Journal, 82(iii), 320-338.

Swain, M., \& Lapkin, S. (2001). Focus on form through collaborative dialogue: Exploring task effects. In M. Bygata, P. Skehan, \& M. Swain (Eds.), Researching pedagogic tasks: Second language learning, teaching and testing (pp. 99-118). London: Longman.

van Drie, J., Van Boxtel, C., Jaspers, J., \& Kanselaar, G. (2005). Effects of representational guidance on domain specific reasoning in CSCL. Computer in Human Behavior, 21, 575-602.

Warschauer, M. (1997). Computer-mediated collaborative learning: Theory and practice. The Modern Language Journal, 81(4), 470-481.

Watanabe, Y., \& Swain, M. (2007). Effects of proficiency differences and patterns of pair interaction on second language learning: Collaborative dialogue between adult ESL learners. Language Teaching Research, 11(2), 121-142.

Wegerif, R., McClaren, B. M., Chamrada, M., Schreuer, O., et al. (2010). Exploring creative thinking in graphically synchronous dialogues. Computers in Education, 54, 613-621.

Wen, Y., Looi, C.K., \& Chen, W. (2011). Towards a model for rapid collaborative knowledge improvement in classroom language learning. In H. Spada et al. (Eds.), International Conference on Computer-Supported Collaborative Learning 2011 (pp. 836-851). Hong Kong.

Wen. Y., Looi, C. K., \& Chen, W.L. (2011). Who are the beneficiaries when CSCL enters into second language classroom. Global Chinese Journal of Computers in Education, 7(1).

Wigglesworth, G., \& Storch, N. (2012). What role for collaboration in writing and writing feedback. Journal of Second Language Writing, 21, 364-374.

Williams, J. (2012). The potential role(s) of writing in second language development. Journal of Second Language Writing, 21, 321-331.

Zhu, E. (2006). Interaction and cognitive engagement: An analysis of four asynchronous online discussions. Instructional Science, 34, 451-480. 